\title{
An objective global climatology of polar lows based on reanalysis data
}

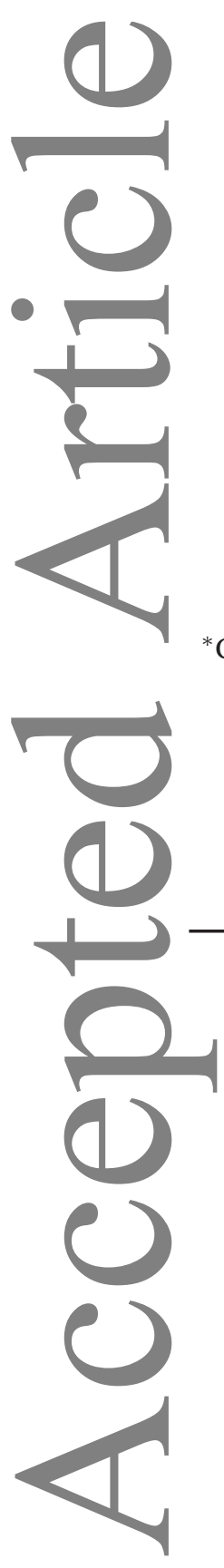

\author{
Patrick Stoll, ${ }^{\mathrm{a} *}$ Rune G. Graversen, ${ }^{\mathrm{a}}$ Gunnar Noer, ${ }^{\mathrm{b}}$ and Kevin Hodges ${ }^{\mathrm{c}}$ \\ a The Arctic University of Norway, Troms $\phi$, Norway \\ ${ }^{\mathrm{b}}$ The Norwegian Meteorological Institute, Troms $\phi$, Norway \\ ${ }^{\mathrm{c}}$ Dept. of Meteorology, University of Reading, Reading, UK
}

*Correspondence to: Patrick Stoll, Department of Physics and Technology, the Arctic University of Norway, 9037 Troms $\emptyset$, Norway. E-mail: patrick.stoll@uit.no

This article has been accepted for publication and undergone full peer review but has not been through the copyediting, typesetting, pagination and proofreading process, which may lead to differences between this version and the Version of Record. Please cite this article as doi: 10.1002/qj.3309 
Here we present an objective global climatology of polar lows. In order to obtain objective detection criteria, the efficacy of several parameters for separating polar lows from other cyclones has been compared. The comparison and the climatology are based on the ERA-Interim reanalysis from 1979 - 2016 and the high-resolution Arctic System Reanalysis from 2000 - 2012. The most effective parameters in separating polar lows from other extra-tropical cyclones were found to be the difference between the sea-level pressure at the centre of the low and its surroundings, the difference in the potential temperature between the sea surface and the $500 \mathrm{hPa}$ level, and the tropopause wind speed poleward of the system. Other parameters often used to identify polar lows, such as the $10 \mathrm{~m}$ wind speed and the temperature difference between the sea surface and the $700 \mathrm{hPa}$ level, were found to be less effective. The climatologies reveal that polar lows occur in all marine basins at high latitudes, but with high occurrence density in the vicinity of the sea-ice edge and coastal zones. The regions showing the highest degree of polar-low activity are the Denmark Strait and the Nordic Seas, especially for the most intense polar lows. In the North Atlantic and Pacific, the main polar-low season ranges from November to March. In the Southern Hemisphere, polar lows are mainly detected between $50-65^{\circ} \mathrm{S}$ from April to October, indicating that this hemisphere compared to its northern counterpart has a two months longer, but less intense, polar-low season. No significant hemispheric long-term trends are observed, although some regions, such as the Denmark Strait and the Nordic Seas, experience significant downward and upward trends in polar lows, respectively, over the last decades. For intense polar lows, a significant decaying trend has been observed for the Northern Hemisphere.

Key Words: mesoscale cyclone; Arctic hurricane; marine cold-air outbreak; detection/ identification criteria; tracking algorithm; long-term trend

Introduction

Polar lows (PLs) are intense mesoscale cyclones occurring over the oceans at high latitudes. Due to their strong winds, they are a threat to fishing, maritime operations, and to life in coastal zones of the polar regions. They are often associated with high amounts of snowfall, so that at landfall they can cause increased avalanche danger and traffic chaos. Furthermore, PLs may lead to fast accumulation of ice on aircrafts and ships (Samuelsen et al. 2015). In particular, PLs can be dangerous since they often develop rapidly, such that hazardous conditions occur suddenly.

Probably the most cited definition of a polar low was formulated by Rasmussen and Turner (2003):

"A polar low is a small, but fairly intense maritime cyclone that forms poleward of the main baroclinic zone (the polar front or other This article is protected by copyright. All rights reserved. 
major baroclinic zone). The horizontal scale of the polar low is approximately between 200 and $1000 \mathrm{~km}$ and surface winds near or above gale force."

Some PLs are referred to as Arctic hurricanes due to their clear central "eye" surrounded by deep convective cloud bands (e.g. Emanuel and Rotunno 1989). However, in contrast to their tropical counterparts, the definition of a PL is vague, and the transition between a PL and the weaker form of a polar mesoscale cyclone is fluent. The scientific community does not agree on criteria for the classification of a cyclone as a PL. This study aims to develop a set of objective identification criteria for the detection of PLs in reanalyses by examining a broad range of previously suggested parameters and to investigate a global PL climatology based on these riteria.

Different PL climatologies have been developed by inspection of satellite images, starting from Wilhelmsen (1985) in the late 1970s and early 1980s for the Nordic Seas (see Fig. 1). For the same region, and for the years 2000 - 2012, Noer et al. (2011) developed the Sea Surface Temperature and Altimeter Synergy for Improved Forecasting of Polar Lows" (STARS) database. Recently Smirnova et al. (2015) proposed a new PL climatology of this region based on satellite passive microwave data for 1995 - 2009 and referred to here as the Smirnova database. The Smirnova database includes considerably more cases than does that of the STARS. This reveals the key problem when investigating and comparing PL climatologies: They are generally based on different criteria and methodologies; two meteorologists might come to different conclusions concerning whether a system is classified as a PL or not, based on a vague notion of what a PL is.

The Nordic Seas are probably the region most often investigated with respect to PL activity, but some other studies have developed climatologies based on satellite images for other regions, such as the Gulf of Alaska for 1975 - 1983 (Businger 1987), the North Pacific 1976 - 1984 (Yarnal and Henderson 1989), the Sea of Japan and North West Pacific for the winter 1995/96 (Fu et al. 1999), and in S SH for 1977 - 1983 (Carleton and Carpenter 1990). However, the subjective nature of PL identification makes comparisons between different climatologies difficult.

Global atmospheric reanalyses can be used to overcome this subjective identification problem. Laffineur et al. (2014) showed that global reanalyses include some PLs, but only a small fraction of the STARS PLs were identified as sea-level-pressure (SLP) minima in reanalysis datasets. By using the European Centre for Medium-Range Weather Forecasts (ECMWF) reanalysis (ERA-I) (Dee et al.

2011), only 13 out of 29 STARS PLs for the period December 1999 to May 2002 were found, although this analysis showed a onsiderable improvement compared to using the older ERA-40 reanalysis, where only 6 systems were identified. Laffineur et al. (2014) also showed that by downscaling ERA-I with a $12 \mathrm{~km}$ resolution model, 22 of the 29 STARS PLs were detected. Kolstad (2011) attempted to circumvent the issue of the underrepresentation of PLs in coarse resolution global reanalysis datasets by compiling a climatology of conditions favourable for PL development. Two criteria were considered, one for the low-level static stability and the other for the upper-level forcing, to obtain the duration for which both criteria are satisfied simultaneously in a given region.

Although global reanalyses show deficits in representing mesoscale systems (Bromwich et al. 2016), Zappa et al. (2014) showed that it is generally possible to identify a considerable amount of PLs in ERA-I. They show that 55\% (19 out of 34) of the STARS PLs of the period 2008 - 2011 could be automatically detected by objective criteria based on the $850 \mathrm{hPa}$ vorticity, the $10 \mathrm{~m}$ wind speed and a measure for the static stability. Michel et al. (2018) detected about $60 \%$ of all STARS PLs in ERA-I with an automatic tracking algorithm based on the Laplacian of the SLP. In the higher resolution ECMWF operational analysis, Zappa et al. (2014) detected $70 \%$ (23 out of 34) of the events. Investigations by Smirnova and Golubkin (2017) estimate that ERA-I represents $48 \%$ (22 out of 46) of the PLs during the cold seasons 2000/01 - 2003/04 from the STARS database, but only 26\% (41 out of 158) from the Smirnova 


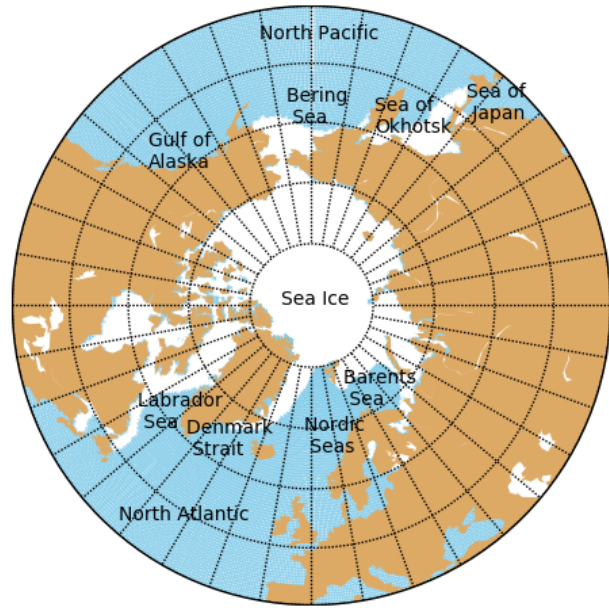

(a)

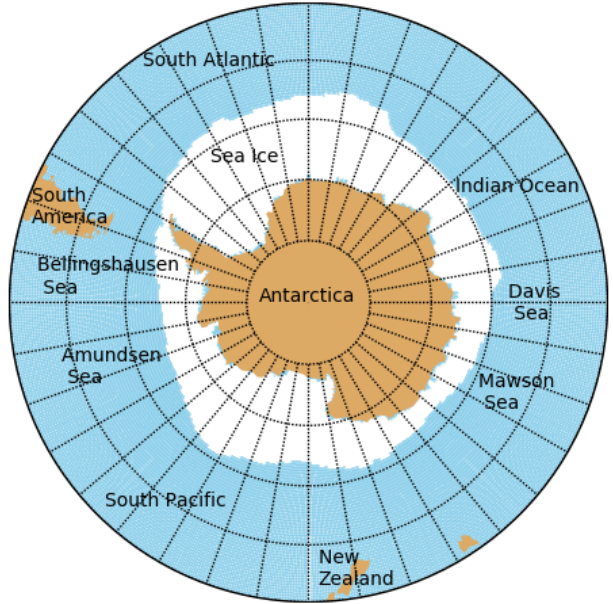

(b)

Figure 1. Map of the polar region of the a) Northern and b) Southern hemisphere. White colour denotes areas with more than $20 \%$ mean sea ice cover during the main polar low season, being for a) November - April and for b) April - October, for the years 1979-2016 from ERA-I.

database. Further, they show that the recently developed high-resolution Arctic System Reanalysis (ASR) version 1 (Bromwich et al. 2016) represents $89 \%$ (41 out of 46) of the PLs from the STARS dataset and 66\% (104 out of 158) from the Smirnova dataset. The improvement is explained by the improved representation of mesoscale systems in this high-resolution reanalysis (Smirnova and Golubkin 2017). The conclusion from this comparison of different reanalysis products indicates a considerable improvement of ASR over ERA-I in terms of PL representation; the ECMWF operational-analysis used by Zappa et al. (2014) and ERA-I downscaled with $2 \mathrm{~km}$ resolution mesoscale model as performed by Laffineur et al. (2014) are still missing a higher proportion of STARS PLs than

ASR. Although the studies used different time periods and methodology, ASR could be regarded as one of the most reliable and consistent dataset for PL representation in the Arctic.

1

Yanase et al. (2016) has also explored PLs in reanalyses developing an objective PL climatology for the Sea of Japan based on the Japanese Reanalysis, JRA-55, from 1979 - 2015, and based on the same approach as Zappa et al. (2014). Using a different approach, Zahn and von Storch (2008) created a PL climatology for the North Atlantic sector for the years 1948 - 2006 by downscaling the global NCEP/NCAR reanalysis with a regional climate model with a resolution of about $50 \mathrm{~km}$. Chen and von Storch (2013) applied the same methodology for the North Pacific sector for the years 1948 - 2010.

Objective PL climatologies depend crucially on criteria applied in order to detect PLs from the whole variety of cyclonic features that are present in the data. Commonly, a threshold for the strength of the SLP minima, or for the vorticity extrema, are imposed, to ensure a certain intensity of the system. Some other additional criteria that are often applied, are presented in the following.

Because PLs develop only over sea areas and dissipate rapidly after making landfall, it is commonly set as a criteria that they are present over open water. The PL definition of Rasmussen and Turner (2003) includes a condition for near or above gale force surface winds, which is generally considered as the maximum of the near-surface wind speed in a certain radius around the PL centre. Often, a threshold of $15 \mathrm{~m} \mathrm{~s}^{-1}$ in a radius of $2.5^{\circ}$ around the centre, is applied (e.g. Yanase et al. 2016). However, global reanalyses such as ERA-I have been shown to under-represent maximum wind speeds associated with PLs (e.g. Zappa et al. 2014), making a strict application of the wind criteria problematic. In ASR the near-surface wind were observed to be more realistic (Smirnova and Golubkin 2017). 
Even though the definition of Rasmussen and Turner (2003) does not mention the occurrence of PLs in marine cold-air outbreaks (MCAOs), there seems to be a general agreement within the scientific community that an MCAO is required for a cyclone to be classified as a PL. This is partly taken into account in the widely applied static-stability criterion, given by a difference between the sea-surface temperature (SST) and the overlying atmospheric temperature, either at 500 hPa (e.g. Zahn and von Storch 2008; Zappa et al. 2014), at 700 hPa (e.g. Bracegirdle and Gray 2008; Kolstad 2011) or at 850 hPa (e.g. Papritz et al. 2015). Commonly, a threshold of SST $-T_{500}>43 \mathrm{~K}$ is used, although Terpstra et al. (2016) and Smirnova and Golubkin (2017) argue that this threshold excludes a considerable amount of PL cases. Bracegirdle and Gray (2008) investigated different temperature parameters, and found the difference between the wet-bulb potential temperature at $700 \mathrm{hPa}$ and the SST to be the most effective of their considered parameters to separate PLs from other cyclones. To our knowledge the study of Bracegirdle and Gray (2008) was the first to objectively compare the effectiveness of different parameters for PL detection. As indicated above, the research community does not agree on a set of parameters d thresholds for objective PL detection, and a comprehensive comparison of criteria is still lacking. In addition, an important part of the PL definition formulated by Rasmussen and Turner (2003), the formation poleward of the main baroclinic zone, has to our nowledge previously not been used as a criteria for PL detection.

This study aims to objectively compare the efficacy of different parameters for the identification of PLs and to apply the derived criteria to the development of an objective, global PL climatology. The paper is structured as follows: After presenting the methods and data in Section 2, the results are divided into two parts. In Section 3, the efficacy of the different parameters for PL identification from eanalysis datasets based on the subjective STARS dataset is compared, and in Section 4, the obtained global PL climatologies based on the application of the derived most effective criteria are analysed. The paper ends with a discussion and conclusion in Section 5.

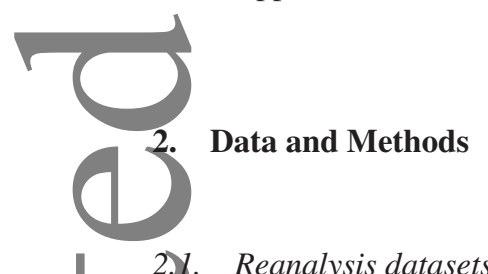

\subsection{Reanalysis datasets}

The ERA-I is a time-consistent and homogeneous global, atmospheric reanalysis product at a T255 horizontal spectral resolution, which corresponds to a grid spacing of about $80 \mathrm{~km}$, and with 60 vertical sigma levels of which 12 are below $850 \mathrm{hPa}$ (Dee et al. 11). ERA-I is produced using four-dimensional, variational data assimilation with a 12-h window. The analysis data are provided and retrieved with a 6-hourly time step and a horizontal spacing of $0.5^{\circ}$. To obtain a reasonable time resolution for the tracking of mesoscale cyclones, the time resolution of the vorticity fields is increased to become 3-hourly by using the 3-and 9-h forecasts starting at 0:00 and 12:00 UTC every day. Other fields are not extended to 3-hourly resolution, since not all (compare Table 1) can be retrieved from the ERA-I forecast. For this study full-year data for 1979 - 2016 for both hemispheres are used.

The recently released Arctic System Reanalysis (ASR) version 2 is a regional reanalysis of the greater Arctic (north of $\sim 40^{\circ} \mathrm{N}$ ) balsed on the Weather Research and Forecasting Model (WRF) version 3.6.0 with adaptations relevant for polar regions (Bromwich et al. 2017). It has a horizontal grid resolution of $15 \mathrm{~km}$, has 71 vertical eta levels, of which 25 are below $850 \mathrm{hPa}$, and is produced from 2000 to 2012. ERA-I is used for the lateral boundary condition and for spectral nudging above $100 \mathrm{hPa}$. ASR applies three-dimensional, variational data assimilation with a 3-h window to include additional in-situ measurements, GPS radio occultation and radiance data from numerous satellite platforms, including 10 m ocean wind speed information. The output fields from ASR are provided 3-hourly on a polar stereographic grid. 


\subsection{STARS polar low list}

The STARS dataset version 2 provides a list of 185 PL tracks over the Nordic Seas from January 2001 to March 2011 (Noer et al. 2011). The PLs are subjectively identified by forecasters at the Norwegian Meteorological Institute by inspection of satellite infrared data, scatterometer winds and the operational weather forecasting model HIRLAM at $4 \mathrm{~km}$ resolution. Recently, the STARS dataset has become the probably most frequently-used record of manually-detected PLs. It has previously been utilized as a basis for investigation of PL development (e.g. Terpstra et al. 2016; Rojo et al. 2015), for evaluation of PL occurrence in different datasets (e.g. Laffineur et al. 2014; Smirnova and Golubkin 2017), and the evaluation of objective detection methods (e.g Zappa et al. 2014).

\section{Tracking algorithm}

veral methods are applied for the automatic detection and tracking of PLs in models and reanalyses. They are based on the detection of local minima in the SLP (e.g. Zahn and von Storch 2008), of local maxima in the Laplacian of the SLP (e.g. Michel et al. 2018), or on local extrema in the relative vorticity (e.g. Zappa et al. 2014). To our knowledge no study has found particular evidence for the advantage of one method over the other for the detection of PLs. For extra-tropical cyclones in general Neu et al. (2013) found little evidence for differences in statistics between the detection algorithms based on vorticity and SLP.

In this study, the objective tracking algorithm (Hodges 1995, 1999) is applied to the relative vorticity at $850 \mathrm{hPa}$. The algorithm detects cyclonic features from which PLs will be identified. Tracking routines for PLs often utilize a spatial bandpass filter to focus on the mesoscale nature of PLs, and hence to remove planetary-, synoptic- and micro-scale local features. For ERA-I, the spherical harmonic fast spectral transform, and for ASR, the discrete cosine transform filter is applied to retain global wavenumbers 40 - 100 quivalent to mesoscale feature with scales of $200-1000 \mathrm{~km}$. The former method only applies to global data and can therefore not be used for ASR. A spectral taper is also utilized in order to suppress Gibbs oscillations (Hoskins and Sardeshmukh 1984). However, ynoptic-scale systems are not completely excluded by this filter. The same algorithm has recently been used for the detection of PLs by Zappa et al. (2014) in the Nordic Seas and by Yanase et al. (2016) in the Sea of Japan. However, in this study it is applied to a global

and a greater-Arctic-covering reanalysis datasets.

The algorithm tracks local maxima in the T40 - 100 filtered vorticity at $850 \mathrm{hPa}\left(\xi_{f, 850}\right)$ in the Northern hemisphere $(\mathrm{NH})$ above $10^{-5} \mathrm{~s}^{-1}$ from the 3-hourly fields by first initializing tracks based on a nearest neighbour method and then minimizing a cost function in order to produce the smoothest set of tracks. In the Southern hemisphere (SH), cyclones are tracked in the same way for orticity minima below $-2 \cdot 10^{-5} \mathrm{~s}^{-1}$. The identified tracks are henceforth referred to as TRACK cyclones. They include all kinds of cyclonic features, such as mesoscale lows, frontal zones, orographic shear zones and remnants of synoptic-scale lows that have not fully been removed by the filter. For systems with several small cyclonic cells, such as dual PLs, only the most intense system within a radius of $220 \mathrm{~km}$ is considered. Note that a link to the dataset of the TRACK cyclones is given in the acknowledgements.

\subsection{Representation of STARS PLs in TRACK cyclones}

In Section 3, PLs will be compared to all tracked cyclones. For this, the TRACK cyclones that correspond to a PL from the STARS dataset are identified. A STARS PL has a corresponding TRACK cyclone, if it matches in a radius of less than $250 \mathrm{~km}$ in more than half of its time steps with the same TRACK cyclone. A STARS-matched PL is defined as the part of the corresponding TRACK cyclone, where the matching is satisfied. These STARS-matched PL are investigated in the following.

This article is protected by copyright. All rights reserved. 
The distance of $250 \mathrm{~km}$ was chosen from consideration that the $\xi_{f, 850}$ extrema in the reanalysis dataset can be displaced in comparison to the subjectively detected PL centre in the satellite images. Bracegirdle and Gray (2008) estimate that displacement errors between subjectively identified polar mesoscale cyclones and features from a model-based cyclone database in the order of $300 \mathrm{~km}$ can occur, but applied a radius of $200 \mathrm{~km}$ by arguing that the maximum displacement seldomly occurs. The sensitivity of the matching was examined with a radius of $200 \mathrm{~km}$ and $300 \mathrm{~km}$ and almost the same results were obtained as for a radius of $250 \mathrm{~km}$.

It was also decided that a STARS PL has to match in more than half of its time steps with the same TRACK cyclone, in contrast to all time steps, since the initialization and decaying time can vary for cyclones between the datasets. Nevertheless, as presented below, most STARS PLs that match with one TRACK cyclone do so for all time steps.

\subsubsection{ERA-I}

In ERA-I, only PLs from the STARS dataset with a duration of at least 6 hours are considered, such that they are represented in at least one time step in the 6-hourly ERA-I analysis data. Note that only the vorticity is extended to 3-hourly time resolution, as described in Section 2.1, to obtain a time resolution sufficient for tracking of mesoscale cyclones. As a result, 138 out of the 185 STARS PLs are f a duration of at least 6 hours, out of which 109 are matched with a TRACK cyclone in ERA-I. Of these, 76 PLs matched for all STARS time steps, and the remaining 33 for more than half of the STARS time steps. Three pairs out of the 109 STARS PLs are associated with the same TRACK cyclones within an overlapping time window. This is due to multiple PL events documented in the STARS dataset*. These 3 pairs are merged, such that 106 STARS-matched PLs remain for ERA-I.

Occurrence over open water is commonly required as criterion for PLs. For example, Zappa et al. (2014) excludes in their detection algorithm TRACK cyclones with an ocean fraction smaller than $75 \%$ within a radius of $1^{\circ}$. For the comparison in Section 3 , only the time steps where the TRACK cyclone is located over open water are included. Open water is here defined as within a circle of radius $220 \mathrm{~km}$ (equivalent to $2^{\circ}$ latitude) with more than $75 \%$ of the grid cells having water, as opposed to both land and sea ice. Of the 106 STARS-matched PLs, 94 have at least one time step occurring over open water. These 94 STARS-matched PLs are used for the development of the PL criteria in Section 3. The 12 excluded cases occur close to the coast or the ice edge in the matching time steps, nd are represented closer to the land or ice in ERA-I than in the STARS dataset. Analyses of using different radii and fraction of water cover compared to the chosen values show negligibly small differences in PL exclusion.

\section{2. $A S R$}

Since all the ASR data are obtained at 3-hourly time resolution, PLs from the STARS dataset with a duration of at least 3 hours are considered. Out of the 185 STARS PLs, 163 are of a duration of at least 3 hours, and of these, 139 match with a TRACK cyclone in ASR. Out of these, 115 PLs match for all STARS time steps, and the remaining 24 for more than half of the STARS time steps. The same 3 pairs of PLs as in ERA-I are identified as multiple PLs and merged, such that 136 STARS-matched PLs remain from ASR. Out of these, 123 have at least one time step with occurrence over open water, and these remaining 123 STARS-matched PLs are used in Section 3.

The comparison of the PL representation between the two reanalyses reveals that the matching is more often satisfied in ASR (139 out of $163=85 \%)$ than in ERA-I $(109$ out of $138=79 \%)$, that it is more often satisfied in all time steps in ASR $(115$ out of $139=$

*STARS PL numbers: 7 and 8,84 and 85 from the northern list, and 19 and 20 from the southern list. 
$83 \%$ ) than in ERA-I (76 out of $109=70 \%)$, and that the STARS-matched PLs in ASR more often have at least one time step occurring over open water $(123$ out of $136=90 \%)$ than in ERA-I (94 out of $106=87 \%)$. This shows the improved PL representation in ASR in comparison to ERA-I, even though ASR includes 3-6hourly events that are often less well represented in reanalysis than longer lasting systems.

\section{Development of polar low identification criteria}

In this section, different parameters are compared for the full set of extra-tropical cyclones and the subset of STARS-matched PLs, in order to find effective criteria to separate the PLs from other cyclones. These criteria will be applied in Section 4 for the detection of PL's in the reanalysis datasets. Therefore, the distribution of different parameters of the STARS-matched PLs and the large set of all TRACK cyclones, where the latter represents the whole variety of cyclonic systems, including PLs, are compared. In the following the prefix "TRACK" and "STARS-matched" are often skipped.

Table 1 summarizes the parameters considered in order to separate the PLs from other cyclones. Here, all parameters that have been
found in literature in connection to PL detection from model products, are compared. Some additional parameters that were considered
as being possibly useful for PL detection, as for example the planetary boundary layer height $(\mathrm{PBH})$, the gradient in the equivalent
$\left(U_{t r, p}\right)$ are also included. Although it is still possible that other parameters not considered here may show higher skills for PL detection,
we believe that the parameter list of Table 1 covers the state-of-the-art knowledge of parameters important for PLs. Note that the wind speed $U=\sqrt{u^{2}+v^{2}}$ in this article always refers to the magnitude in the horizontal wind vector with zonal and meridional wind components $u$ and $v$. The potential temperature of air with temperature $T$ at pressure $p$ is calculated by $\theta=T\left(p_{0} / p\right)^{\kappa}$ with reference pressure $p_{0}=1000 \mathrm{hPa}$ and the Poisson constant for dry air $\kappa=2 / 7$. For the potential temperature at the sea surface $\left(\theta_{\mathrm{SST}}\right) p=\mathrm{SLP}$ is used. The equivalent potential temperature is calculated by $\theta_{e}=\theta \cdot \exp \left(L_{v} \cdot r_{v} / C_{p} \cdot T\right)$ with the water-vapour mixing ration $r_{v}$, the latent heat of vaporization $L_{v}=2.501 \cdot 10^{6} \mathrm{~J} \mathrm{~kg}^{-1}$ and the heat capacity of dry air $C_{p}=1.006 \cdot 10^{3} \mathrm{~J} \mathrm{~kg}$.

Poleward properties are obtained from grid cells of higher latitude along the same longitude for ERA-I with spherical coordinates, and from grid cells of higher latitude within longitudes of $\pm 1^{\circ}$ compared to the cyclones centre for ASR, having a stereographic projection. For most parameters, the mean and maximum value within different radii are compared, to find the most effective set-up. The arameters are separated into three categories: intensity, MCAO and polar-front criteria, where the latter determines whether the system is poleward of the polar-front. Each parameter is put into the category where it shows the highest dependence on the other parameters within the category: A high dependence of two parameters is found, if they, applied as criteria, exclude the same cyclones. Some parameters that generally would not be considered as MCAO-criteria are hereby put into that category. Examples of these parameters are the maximum tropopause pressure $\left(p_{t r}\right)$, as suggested by Kolstad (2011), and the potential temperature at the tropopause $\left(\theta_{t r}\right)$, as suggested by Terpstra et al. (2016). These are both applied to identify areas of upper-level forcing. Another example is $\nabla \theta_{e, 850}$, which nvestigated for the efficacy to exclude systems close to the main baroclinic zone. However, the classification of the parameters into different types of criteria is done for clarity reasons only and does not influence the result of obtaining the most skilful PL identification parameters.

Within the intensity criteria, the filtered vorticity $\left(\xi_{f, 850}\right)$ and the difference of the mean SLP within a circle of radius $r$ and the SLP of the cyclone centre ( $\overline{\mathrm{SLP}}$ - SLP), both consider intensity within the mesoscale. The $\xi_{f, 850}$ is the spectrally filtered value, and $\overline{\text { SLP }}$ - SLP measures the deepness of the low compared to the local surrounding.

This article is protected by copyright. All rights reserved. 
Table 1. Parameters compared for their efficacy to identify PLs from the large set of cyclones. Horizontal lines separate parameters of different types, with the first being the intensity criteria, the second the marine cold-air outbreak (MCAO) criteria, and the third the polar-front criteria. Parameters denoted with * are typically smaller for PLs than for average cyclones. A radius of $1^{\circ}$ lat is equivalent to approximately $110 \mathrm{~km}$.

\begin{tabular}{|c|c|c|c|}
\hline Parameter & Symbol & Type & $r\left[^{\circ}\right.$ lat $]$ \\
\hline $\mathrm{T} 40$ - T100 filtered relative vorticity at $850 \mathrm{hPa}$ & $\xi_{f, 850}$ & point & 0 \\
\hline Maximum $10 \mathrm{~m}$ wind speed in radius $r$ & $U_{10 m}$ & $\max$ & $1,2,3$ \\
\hline Sea level pressure & $\mathrm{SLP}$ * & point & 0 \\
\hline Difference of the mean SLP in radius $r$ and the SLP of the cyclone centre & $\overline{\text { SLP }}-$ SLP & mean - point & $1,2,3,5$ \\
\hline Mean temperature at 500 and $700 \mathrm{hPa}$ in radius $r$ & $T_{500}, T_{700}{ }^{\star}$ & mean & 1 \\
\hline Mean sea-surface temperature in radius $r$ & $\mathrm{SST}^{\star}$ & mean & 1 \\
\hline Mean equivalent potential temperature at 700 and $850 \mathrm{hPa}$ in radius $r$ & $\theta_{e, 700}, \theta_{e, 850}{ }^{\star}$ & mean & 1 \\
\hline Mean and maximum difference between the SST and $T_{500} / T_{700}$ in $r$ & $\mathrm{SST}-T_{500 / 700}$ & mean, max & 1 \\
\hline Difference in the potential temperature at the sea-surface and $p=500 / 700 / 850 \mathrm{hPa}$ & $\theta_{\mathrm{SST}}-\theta_{p}$ & mean, max & $1,2,3$ \\
\hline Difference in the equivalent potential temperature of the same levels & $\theta_{e, S S T}-\theta_{e, p}$ & mean, max & $1,2,3$ \\
\hline MCAO criteria used by Kolstad and Bracegirdle (2008) with $p=500 / 700 \mathrm{hPa}$ & $\mathrm{MCAO}_{1, p}$ & mean, max & 1 \\
\hline MCAO criteria used by Bracegirdle and Kolstad (2010) at $700 \mathrm{hPa}$ & $\mathrm{MCAO}_{2}$ & mean, max & 1 \\
\hline Mean and minimum potential temperature of the tropopause in radius $r$ & $\theta_{t r}{ }^{\star}$ & mean, min & $1,3,5$ \\
\hline Difference in the potential temperature of the sea-surface and the tropopause & $\theta_{\mathrm{SST}}-\theta_{t r}$ & mean, max & 1,3 \\
\hline Maximum tropopause pressure within radius $r$ & $p_{t r}$ & $\max$ & $3,4,5$ \\
\hline Mean planetary boundary layer height within radius $r$ & $\mathrm{PBH}$ & mean & $1,2,3$ \\
\hline Maximum gradient of the $850 \mathrm{hPa}$ equivalent potential temperature in radius $r$ & $\nabla \theta_{e, 850}{ }^{\star}$ & $\max$ & $3,4,5$ \\
\hline Mean of the total column water in radius $r$ & water * & mean & 1 \\
\hline Maximum tropopause wind speed poleward of the cyclone centre & $U_{t r, p}{ }^{\star}$ & $\max$ & Poleward \\
\hline Maximum $500 \mathrm{hPa}$ wind speed poleward of the cyclone centre & $U_{500, p}{ }^{\star}$ & $\max$ & Poleward \\
\hline Maximum of the gradient of the $\theta_{e, 850}$ poleward of the cyclone centre & $\nabla \theta_{e, 850, p}{ }^{\star}$ & $\max$ & Poleward \\
\hline
\end{tabular}

\section{criteria, based on the investigations with ERA-I.}

The tropopause properties, such as the potential temperature $\left(\theta_{t r}\right)$, the pressure $\left(p_{t r}\right)$ and the wind speed $\left(U_{t r}\right)$, are taken from the 2PVU level. For ASR, only a selection of the parameters from Table 1 were investigated, since some, such as the tropopause properties and the PBH, were not directly available, and others, such as the equivalent potential temperature, were not expected to lead to improved

The comparison includes two MCAO criteria suggested from recent studies: $\mathrm{MCAO}_{1, p}=\frac{\theta_{\mathrm{SST}}-\theta_{p}}{S L P-p}$, applied by Kolstad and Bracegirdle (2008) at the pressure level $p=700 \mathrm{hPa}$ and here also at $p=500 \mathrm{hPa}$, and $\mathrm{MCAO}_{2}=\frac{L}{Z_{700}}\left(\ln \theta_{\mathrm{SST}}-\ln \theta_{700}\right)$ from Bracegirdle and Kolstad (2010), with $Z_{700}$ being the geopotential height at $700 \mathrm{hPa}$ and $L=7.5 \cdot 10^{5} \mathrm{~m}$, a scaling height. The latter parameter is, together with $p_{t r}$, used by Kolstad (2011) to identify areas with favourable PL conditions.

In the following, the maximum value of these parameters during the lifetime of the STARS-matched PLs and all cyclones, including

PLs, are computed, and their distributions are compared. The more the distributions differ from each other, the better the variable is for separating PLs from non-PL cyclones. Here, it is implicitly assumed that only a small amount of the cyclones are PLs. Note that for ariables that are found to be smaller for PLs than for all cyclones, such as SLP, SST, $T_{500 / 700}, \theta_{e, 700 / 850}, \theta_{t r}, \nabla \theta_{e, 850}$, water, $U_{t r, p}$ and $U_{500, p}$, the minimum values during the lifetime are compared.

\subsection{ERA-I}

It was chosen to compare the identified 94 STARS-matched PLs to all TRACK cyclones occurring in potentially PL active regions and seasons, since the aim is to find effective parameters to distinguish between the two. For ERA-I, all cyclones over open water north of $30^{\circ} \mathrm{N}$ in the time range between Jan - Apr and Oct - Dec 2003, representing the PL active season, are taken for the comparison. This sample includes 8301 cyclones. Because of the large amount of cyclonic events, it is assumed that one year of cyclones is representative for the distribution of all cyclones in the same season during the whole dataset. This assumption is supported by a comparisons of the 


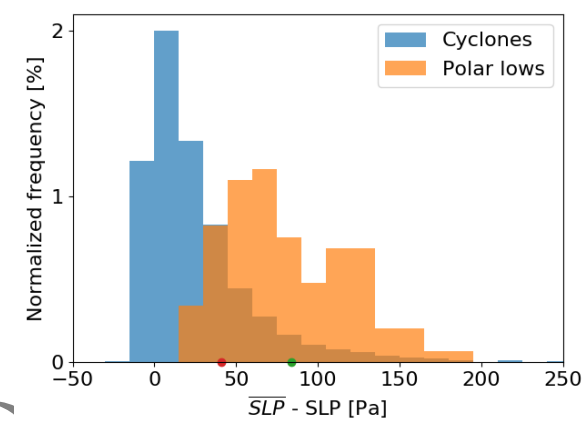

(a) $\overline{\text { SLP }}$ - SLP

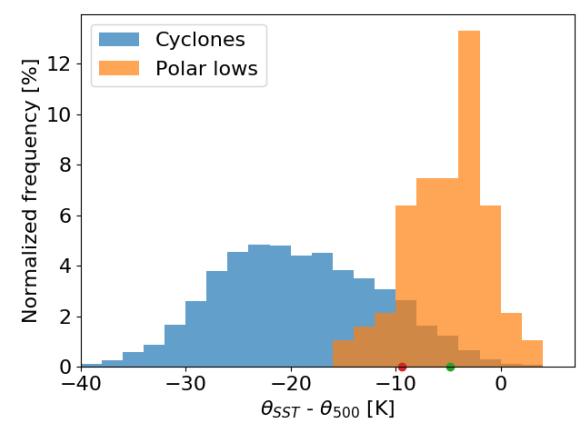

(b) $\theta_{\mathrm{SST}}-\theta_{500}$

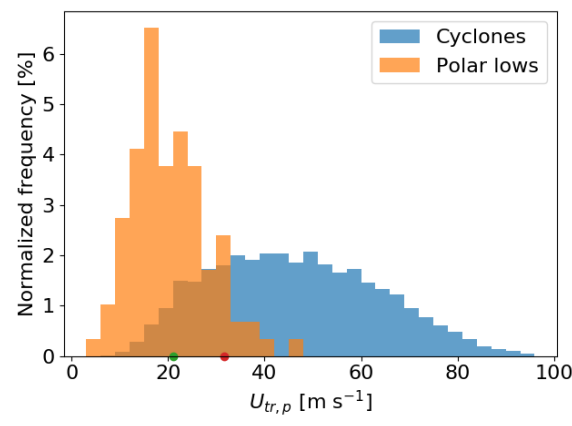

(c) $U_{t r, p}$

Figure 2. Normalized distributions of a) the difference between the mean SLP in a radius of $110 \mathrm{~km}$ and the SLP of the cyclone centre, b) the maximum potentialtemperature difference between the sea surface and the $500 \mathrm{hPa}$ level within a radius of $110 \mathrm{~km}$, and c) the tropopause wind speed poleward of the system for all types of cyclones and the STARS-matched PLs of ERA-I. The green and red dot mark the mean and the 10th percentile for a) and b) and the 90th percentile for c) of the PLs. These criteria were found to be the most effective for discrimination between PLs and other cyclones in ERA-I.

cyclone distributions for a few parameters for the whole timespan of the dataset ranging from 1979 to 2016 and for the year of 2003 only (not shown). The year 2003 is an arbitrary choice.

?

3.1.1. The measure for the efficacy of different parameters for PL detection

Examples of the comparison between the distributions of the parameters $\overline{\mathrm{SLP}}-\mathrm{SLP}, \theta_{\mathrm{SST}}-\theta_{500}$ and $U_{t r, p}$ for PLs and cyclones are shown in Figure 2. For all three of these parameters, the distributions for all cyclones and PLs differ considerably, with PLs showing deeper lows, lower static stability, and lower maximum tropopause wind poleward of the system.

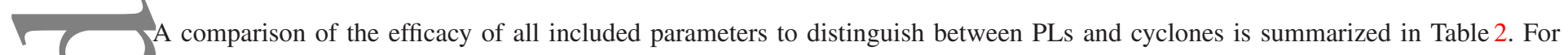
parameters, where the mean and maximum values in different radii are tested, the table includes only the most effective set-up for distinguishing between PLs and cyclones. The efficacy of a parameter for PL detection is measured as follows: The 10th percentile of the parameters for the PLs (red dot in Fig. 2 and fourth column in Table 2) are calculated. For parameters that are generally found to be lower for PLs than for cyclones, such as SLP, the 90th percentile is calculated instead. Then, the fraction of cyclones that remain below (above) this boundary is calculated and presented in column 5 of Table 2 . If the 10th (90th) percentile threshold excludes a large part of the cyclones, the variable is regarded as being effective for distinguishing PLs from other cyclones.

It was chosen to take the $\mathrm{n}$-th percentile instead of "mean - $\mathrm{m} \times$ standard-deviation" since the distribution may not be normal (see

.g. Fig. 2a). The 10th percentile was chosen from a consideration to only falsely exclude a few PLs, but at the same time disregard as many cyclones as possible. Application of the 5th percentile instead of the 10th leads to slightly weaker criteria, whereby too few cyclones are excluded. However, it leads to the same conclusions regarding the most effective parameters.

\section{Most effective criteria - the PL-IC}

The three most effective parameters of each category are found to be 1) intensity criteria: a difference of the mean SLP within a radius of $110 \mathrm{~km}$ and the SLP of the cyclone centre, $\overline{\mathrm{SLP}}-\mathrm{SLP}>0.4 \mathrm{hPa}, 2) \mathrm{MCAO}$ criteria: a maximum difference of the potential temperature at the sea-surface and $500 \mathrm{hPa}$ within a radius of $110 \mathrm{~km}, \theta_{\mathrm{SST}}-\theta_{500}>-9.4 \mathrm{~K}$, and 3) polar-front criteria: a maximum tropopause wind poleward of the system, $U_{t r, p}<31.3 \mathrm{~m} \mathrm{~s}^{-1}$. In the following, these three parameters are referred to as the PL identification criteria (PLIC). Column 6 in Table 2 depicts the fraction of cyclones that have not been excluded by the PL-IC of the other two categories, and that are excluded by applying the 10 th percentile threshold of the parameter. It is found that $\overline{\mathrm{SLP}}-\mathrm{SLP}>0.4 \mathrm{hPa}$ and $\theta_{\mathrm{SST}}-\theta_{500}>-9.4 \mathrm{~K}$ 
Table 2. Comparison of the efficacy of different parameters for the selection of PLs from the large set of all cyclones in ERA-I. The first column expresses the used parameter. The second column depicts whether the value at a point, the maximum or mean value in the radius given by column 3 is taken. For $U_{t r, p}, U_{500, p}$ and $\nabla \theta_{e, 850, p}$ the maximum value poleward of the system is considered. The fourth column presents the value of the 10th percentile of the PLs, meaning that $90 \%$ of the PLs have a higher value. For parameters, that are lower for PLs than for all cyclones, marked with * the 90 th percentile is calculated instead. The fifth column shows the fraction of cyclones below the 10th (above the 90th) percentile. The higher the value, the more effective is the parameter. Horizontal lines separate the different categories of criteria. The most effective parameter of each category is denoted by red colour in the first column. These are the PL identification criteria (PL-IC). The sixth column presents the fraction of cyclones that are excluded by the 10th (90th) percentile of PLs after the PL-IC from the other two categories have been applied. The seventh column gives the fraction of cyclones after application of the PL-IC, which are below (above) the 10th (90th) percentile. Values around $10 \%$ or below show that this criteria would not contribute to an improved separation of PLs from all cyclones.

\begin{tabular}{|c|c|c|c|c|c|c|}
\hline Parameter & Type & $\begin{array}{c}\text { Radius } \\
{[\mathrm{km}]}\end{array}$ & $\begin{array}{l}\text { 10th percentile } \\
\text { of polar lows }\end{array}$ & $\begin{array}{c}\text { Excluded } \\
\text { cyclones [\%] }\end{array}$ & $\begin{array}{l}\text { Excluded cyclones } \\
\text { after } 2 \text { criteria [\%] }\end{array}$ & $\begin{array}{l}\text { Excluded cyclones } \\
\text { after } 3 \text { criteria [\%] }\end{array}$ \\
\hline \multicolumn{7}{|l|}{ Intensity criteria } \\
\hline$\xi_{f, 850}$ & point & 0 & $>5.04 \cdot 10^{-5} \mathrm{~s}^{-1}$ & 71.4 & 58.3 & 22.4 \\
\hline$U_{10 m}$ & $\max$ & 220 & $>13.3 \mathrm{~m} \mathrm{~s}^{-1}$ & 43.3 & 27.0 & 7.7 \\
\hline $\mathrm{SLP}^{\star}$ & point & 0 & $<1006.7 \mathrm{hPa}$ & 49.1 & 16.1 & 2.7 \\
\hline$\overline{\text { SLP }}$ - SLP & mean-point & 110 & $>0.4 \mathrm{hPa}$ & 77.9 & 63.7 & 0 \\
\hline$\overline{\text { SLP }}$ - SLP & mean-point & 330 & $>2.3 \mathrm{hPa}$ & 74.9 & 53.3 & 2.2 \\
\hline \multicolumn{7}{|c|}{ Marine cold air outbreak criteria } \\
\hline$T_{500}{ }^{\star}$ & mean & 110 & $<241.4 \mathrm{~K}$ & 81.0 & 52.6 & 2.7 \\
\hline$T_{700}{ }^{\star}$ & mean & 110 & $<260.3 \mathrm{~K}$ & 72.5 & 45.9 & 2.7 \\
\hline$\theta_{e, 700}{ }^{\star}$ & mean & 110 & $<292.5 \mathrm{~K}$ & 68.3 & 44.6 & 1.1 \\
\hline$\theta_{e, 850}$ * & mean & 110 & $<290.9 \mathrm{~K}$ & 61.6 & 41.5 & 3.3 \\
\hline $\mathrm{SST}^{\star}$ & mean & 110 & $<281.8 \mathrm{~K}$ & 51.4 & 19.1 & 10.4 \\
\hline $\mathrm{SST}-T_{500}$ & $\max$ & 110 & $>41.4 \mathrm{~K}$ & 82.3 & 69.9 & 6.6 \\
\hline $\mathrm{SST}-T_{700}$ & $\max$ & 110 & $>22.8 \mathrm{~K}$ & 73.6 & 67.7 & 13.7 \\
\hline$\theta_{\mathrm{SST}}-\theta_{500}$ & $\max$ & 110 & $>-9.4 \mathrm{~K}$ & 88.5 & 72.3 & 0 \\
\hline$\theta_{\mathrm{SST}}-\theta_{700}$ & $\max$ & 110 & $>-4.1 \mathrm{~K}$ & 79.5 & 66.0 & 7.7 \\
\hline$\theta_{\mathrm{SST}}-\theta_{850}$ & mean & 220 & $>0.0 \mathrm{~K}$ & 72.2 & 64.0 & 14.2 \\
\hline$\theta_{e, S S T}-\theta_{e, 500}$ & mean & 110 & $>-3.1 \mathrm{~K}$ & 65.3 & 46.7 & 6.6 \\
\hline$\theta_{e, S S T}-\theta_{e, 700}$ & $\max$ & 110 & $>4.3 \mathrm{~K}$ & 63.0 & 62.5 & 19.7 \\
\hline$\theta_{e, S S T}-\theta_{e, 850}$ & $\max$ & 110 & $>5.8 \mathrm{~K}$ & 55.3 & 63.4 & 24.6 \\
\hline $\mathrm{MCAO}_{1,500}$ & $\max$ & 110 & $>-20.0 \cdot 10^{-5} \mathrm{~K} \mathrm{~Pa}^{-1}$ & 86.9 & 70.4 & 0 \\
\hline $\mathrm{MCAO}_{1,700}$ & $\max$ & 110 & $>-14.1 \cdot 10^{-5} \mathrm{KPa}^{-1}$ & 79.2 & 66.3 & 8.7 \\
\hline $\mathrm{MCAO}_{2}$ & $\max$ & 110 & $>-4.0$ & 79.0 & 66.5 & 8.7 \\
\hline$\theta_{t r} \star$ & mean & 330 & $<300.7 \mathrm{~K}$ & 86.1 & 56.0 & 9.3 \\
\hline$\theta_{\mathrm{SST}}-\theta_{t r}$ & mean & 330 & $>-19.0 \mathrm{~K}$ & 88.5 & 65.3 & 11.5 \\
\hline$p_{t r}$ & $\max$ & 330 & $>382 \mathrm{hPa}$ & 53.5 & 13.1 & 4.4 \\
\hline $\mathrm{PBH}$ & mean & 330 & $>902 \mathrm{~m}$ & 53.7 & 45.9 & 16.4 \\
\hline$\nabla \theta_{e, 850}{ }^{\star}$ & $\max$ & 550 & $<7.9 \cdot 10^{-2} \mathrm{~K} \mathrm{~km}^{-1}$ & 37.3 & 29.1 & 23.5 \\
\hline wąter * & mean & 110 & $<10.8 \mathrm{~kg} \mathrm{~m}^{-2}$ & 60.8 & 46.5 & 3.8 \\
\hline \multicolumn{7}{|c|}{ Polar front criteria } \\
\hline$U_{t r, p}{ }^{\star}$ & $\max$ & polew & $<31.3 \mathrm{~m} \mathrm{~s}^{-1}$ & 77.6 & 31.7 & 0 \\
\hline$U_{500, p}{ }^{\star}$ & $\max$ & polew & $<24.8 \mathrm{~m} \mathrm{~s}^{-1}$ & 69.6 & 34.0 & 9.8 \\
\hline$\nabla \theta_{e, 850, p}{ }^{\star}$ & $\max$ & polew & $<7.2 \cdot 10^{-2} \mathrm{~K} \mathrm{~km}^{-1}$ & 31.9 & 19.0 & 20.2 \\
\hline
\end{tabular}

.

exclude about $63.7 \%$ and $72.3 \%$ of the cyclones that have not been excluded by the other two PL-IC. $U_{t r, p}<30.7 \mathrm{~m} \mathrm{~s}^{-1}$ excludes about $31.7 \%$ of the cyclones satisfying the other two PL-IC. The high proportion of cyclones excluded by each of the PL-IC after application of the other two PL-IC shows that these criteria are non-redundant. However, each PL-IC excludes a lower fraction of cyclones after the other two PL-ICs have been applied (column 6) than if they would not have been applied (column 5), meaning that the PL-IC are not completely independent from each other.

These three PL-IC are found to be sufficient for PL detection. The last column of Table 2 shows the proportion of cyclones being excluded by the different parameters after application of all three PL-IC. Note that for the PL-IC themselves, no additional cyclones are excluded, since these parameters were already used for exclusion. The additional application of parameters with a value around 
or below $10 \%$ in the last column would exclude about as many PLs as cyclones, and those parameters do therefore not contribute to a better identification of PLs. This applies for most of the additional parameters. Some examples are presented in Figure 3 for the distributions of the $10 \mathrm{~m}$ wind speed $\left(U_{10 m}\right)$, the total column water, $\theta_{e, S S T}-\theta_{e, 700}, \xi_{f, 850}, \nabla \theta_{e, 850}$, and $p_{t r}$, which all show differences between PLs and cyclones (Figure 3a-c,g-i). After application of the PL-IC, the distributions of PLs and cyclones for most other parameters become similar (Figure 3d-f,j-1). For example, using $\theta_{e, S S T}-\theta_{e, 850}$ as an extra criteria to the PL-IC would exclude an additional $24.6 \%$ cyclones (value in last column of Table 2), but Fig. $3 f$ depicts that none of the additional excluded cyclones is far away from the exclusion threshold (red dot). This implies that $\theta_{e, S S T}-\theta_{e, 850}$ as an additional criteria would not exclude cyclones significantly different from the STARS-matched PLs. The same argumentation is valid for $\theta_{e, S S T}-\theta_{e, 700}$.

Two other parameters, $\xi_{f, 850}$ and $\nabla \theta_{e, 850}$ exclude more than $20 \%$ of the remaining cyclones as additional criteria (see value in last column of Table 2). The comparison of the distributions of these two parameters with and without application of the PL-IC (Fig.3g,h nd $\mathrm{j}, \mathrm{k}$ ) shows that the distributions of the remaining cyclones and PLs are more similar, but not identical. These two parameters were ested as additional PL-IC, and in order to not exclude too many of the matched PLs, the exclusion threshold was lowered from the 10th to the 5th percentile. The characteristics of the resulting climatology with the three PL-IC (presented in Section 4), and the resulting climatology with $\xi_{f, 850}$ and $\nabla \theta_{e, 850}$ as additional criteria are similar to each other (not shown). Since it is considered advantageous to use as few criteria as possible, it was decided to not include $\xi_{f, 850}$ and $\nabla \theta_{e, 850}$ as PL-IC.

The fact that after application of the three PL-IC, the identified cyclones show a similar distribution in almost all parameters to the 94 TARS-matched PLs gives confidence that the criteria perform well for PL detection and that the identified cyclones can be considered to be PLs (see e.g. Fig. 3e,f). A time step of a cyclone that satisfies all three PL-IC in the following discussion will be called a PL point. Most of the STARS PLs $(72$ out of $94=76.6 \%$ ) include at least one PL point, while only a small proportion of the large set of clones $(183$ out of $8301=2.2 \%)$ include a PL point.

(1).

\section{Intensity criteria}

I

In the following, the different parameters within one type of criteria are compared, starting with the intensity criteria. Within the intensity criteria, the filtered vorticity $\xi_{f, 850}$ (Fig. 3g) and a measure for the local depth of the low SLP - SLP (Fig. 2a) are both effective parameters, with the latter being slightly better than the former. The SLP - SLP was found to be the most effective, if the mean was calculated within a radius of $110 \mathrm{~km}$, probably since this best considers the mesoscale nature of PLs. Most of the cyclones excluded by the $\xi_{f, 850}$ criteria are also excluded by the application of the SLP - SLP criteria (comparison of Fig.3g,j and the values in the last two columns of Table 2 for $\left.\xi_{f, 850}\right)$. However, the distribution of $\xi_{f, 850}$ for the identified cyclones is shifted slightly towards weaker systems in comparison to the PL distribution (Fig.3j). This shows that the two intensity criteria are strongly related, but not completely redundant.

The maximum $10 \mathrm{~m}$ wind speed $\left(U_{10 m}\right)$ was found considerably less effective in identifying PLs than SLP - SLP and $\xi_{f, 850}$. The $m$ distributions for PLs and cyclones are relatively similar to each other (Fig. 3a). After application of the PL-IC, the distributions of the identified cyclones and STARS-matched PLs are similar (Fig. 3d). The 10th percentile of $U_{10 m}$ for PLs is found to be $13.3 \mathrm{~m} \mathrm{~s}{ }^{-1}$, lower than the threshold of $15 \mathrm{~m} \mathrm{~s}^{-1}$, which represents gale force, commonly used for detecting PLs from low-resolution reanalyses, (e.g. Zappa et al. 2014; Yanase et al. 2016). It was noticed by e.g. Zappa et al. (2014) that the wind criteria of $15 \mathrm{~m} \mathrm{~s}^{-1}$ excludes a relevant amount of PLs (for their study region 9 out of $34=26 \%$ ), and for our analysis, it was found to exclude a comparable fraction ( 26 out of $94=28 \%$ ). This can partly be explained by an underrepresentation of strong winds associated with PLs in ERA-I, 
as for example found by Smirnova and Golubkin (2017). Another possible reason for the better performance of SLP - SLP and $\xi_{f, 850}$ compared to $U_{10 m}$ is the occurrence of PLs in synoptic-scale MCAOs, which are often associated with large-scale wind speeds in the order of $10 \mathrm{~m} \mathrm{~s}^{-1}$. The first two parameters are considering the occurrence of PLs within a synoptic-scale phenomena, while the $U_{10 \mathrm{~m}}$ can almost be satisfied by the MCAO itself.

\subsubsection{Marine cold air outbreak criteria}

In the following the parameters representing the MCAO criteria are compared. The $\theta_{\mathrm{SST}}-\theta_{500}$ is the most effective parameter for PL identification within the MCAO criteria.

Static stability measures, such as SST $-T_{p}, \theta_{\mathrm{SST}}-\theta_{p}$ and $\mathrm{MCAO}_{1}$, perform in general better for discrimination between PLs and ther cyclones when the upper-level value is obtained from the $p=500 \mathrm{hPa}$ level instead of from the $700 \mathrm{hPa}$ or $850 \mathrm{hPa}$ level. This result is not in contradiction with lower-level temperature differences, for instance $\theta_{\mathrm{SST}}-\theta_{850}$ as applied by Papritz et al. (2015), being more effective for the identification of MCAOs, since the out-breaking air often stays below a strong inversion layer. However, for PLs, deep instability and convection are observed. The out-breaking air is warmed by the sea surface and lifted through the inversion layer until it reaches the upper troposphere Noer et al. (2011).

$\mathrm{MCAO}_{1}$ and $\mathrm{MCAO}_{2}$, which are formulas dependent on the ratio of the $\theta$ differences to pressure/height difference between the vels, do not show improvement in comparison to the difference in $\theta$ between the same two levels. Bracegirdle and Gray (2008) did a similar study to investigate the efficacy of some MCAO criteria for PL detection on the basis of a subjective dataset. They found that the difference in temperature between the $700 \mathrm{hPa}$ level and the sea surface is more effective than between the $500 \mathrm{hPa}$ level and the sea urface. However, they investigated a different temperature parameter and used only a small subjective database of 58 cases of polar mesoscale cyclones (both PLs and weaker systems) during the three months Dec 2001 to Feb 2002.

The comparison reveals that potential temperature performs better in identifying the PLs than the temperature difference between two levels. The former includes the sea-level pressure, making it a more accurate measure of the static stability. Since PLs often coincide with lower SLP than other cyclones (see Table 2), static stability based on $\theta$ rather than on $T$ becomes more distinct for PLs as compared to cyclones. Interestingly, the equivalent potential temperature difference, an even more accurate parameter for the vertical ability since it includes moisture, is not as effective at identifying the PLs. This may be explained by the occurrence of PLs in cold environments where the atmosphere holds very little moisture and, therefore, considering $\theta_{e}$ instead of $\theta$ has only a small effect. In warmer environments, where mid-latitude cyclones develop, and where the atmospheric water content is larger, moisture induces a higher contribution to the static stability.

The temperatures at 500 and $700 \mathrm{hPa}$ also perform well at distinguishing between PLs and other cyclones, but slightly less well than the differences in potential temperature between the same level and the sea surface. The SST on its own does not seem to be a ulcessful parameter for discrimination. This leads to the suggestion that the upper-level temperature is more important than the SST for identification of PLs.

A commonly used threshold for the static stability is the SST $-T_{500}>43 \mathrm{~K}$ evaluated as a mean within a $1^{\circ}$ radius (e.g. Zappa $e t$ al. 2014). Our methodology of calculating the 10th percentile from the PLs would suggest a weaker threshold of $39.7 \mathrm{~K}$ for this parameter (not shown). A threshold of $43 \mathrm{~K}$ of this parameter would exclude $30.9 \%$ of the PLs and therefore appears to be too high. Also, Terpstra et al. (2016) noted that this threshold excludes a considerable amount of PLs in the North Atlantic.

This article is protected by copyright. All rights reserved. 


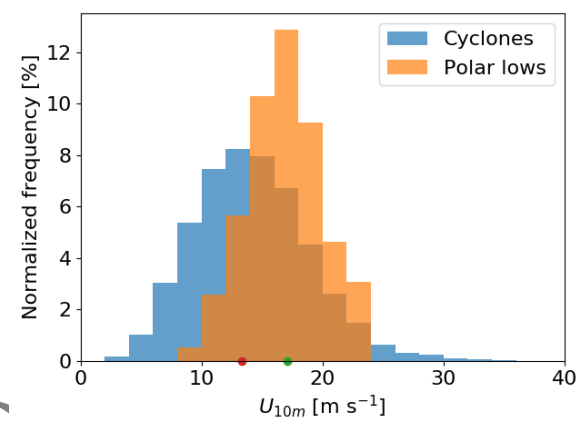

(a) $U_{10 \mathrm{~m}}$

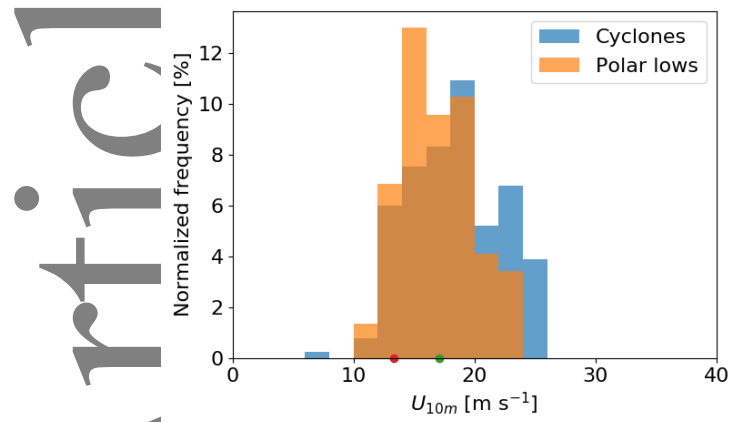

(d) $U_{10 m}$ after PL-IC

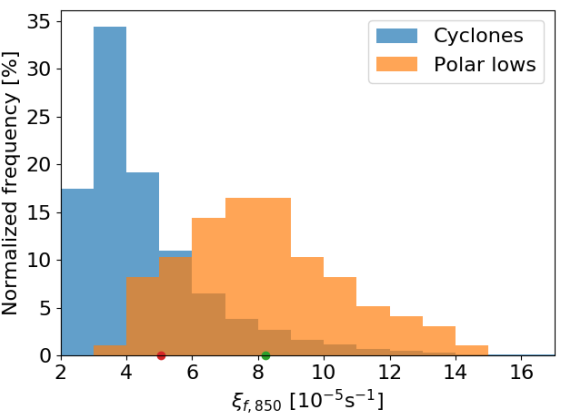

(g) $\xi_{f, 850}$

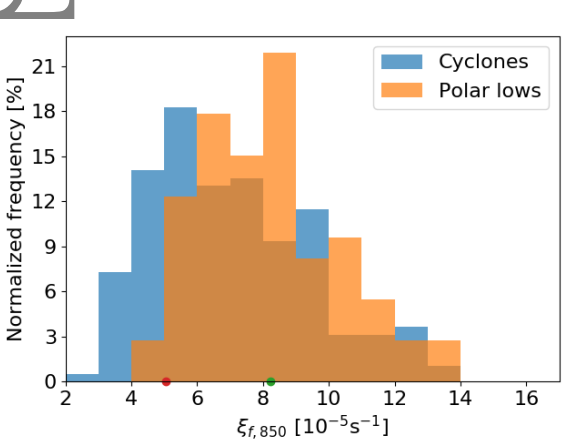

(j) $\xi_{f, 850}$ after PL-IC

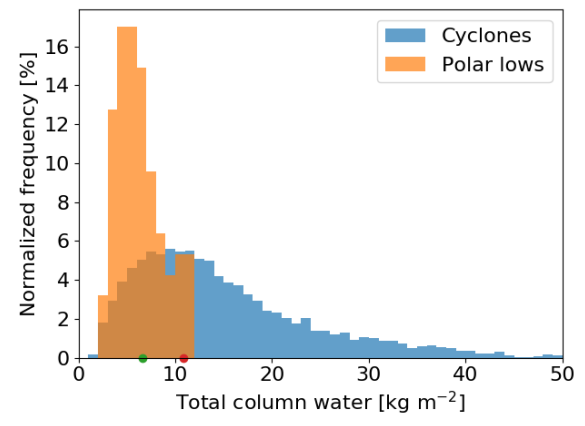

(b) Column water

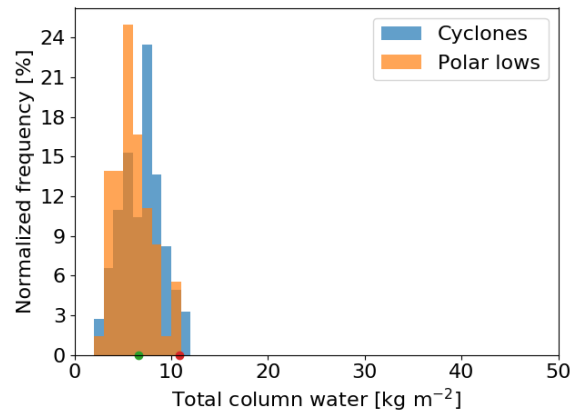

(e) Column water after PL-IC

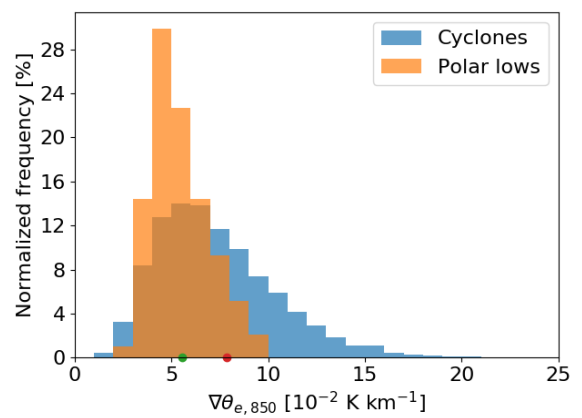

(h) $\nabla \theta_{e, 850}$

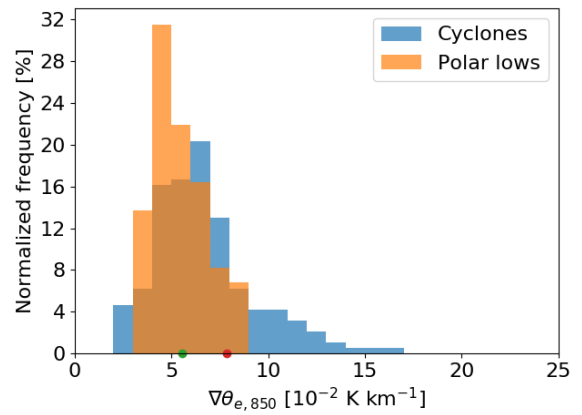

(k) $\nabla \theta_{e, 850}$ after PL-IC

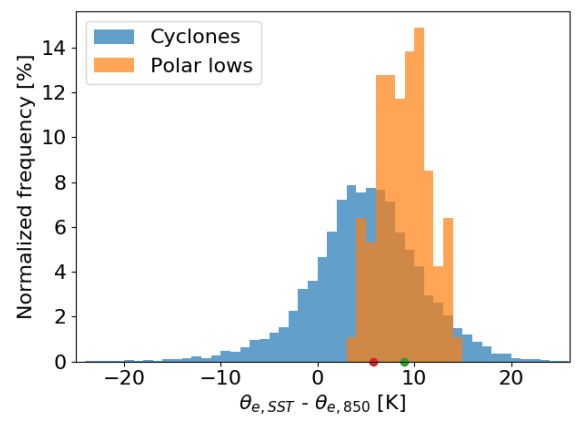

(c) $\theta_{e, S, S T}-\theta_{e, 850}$

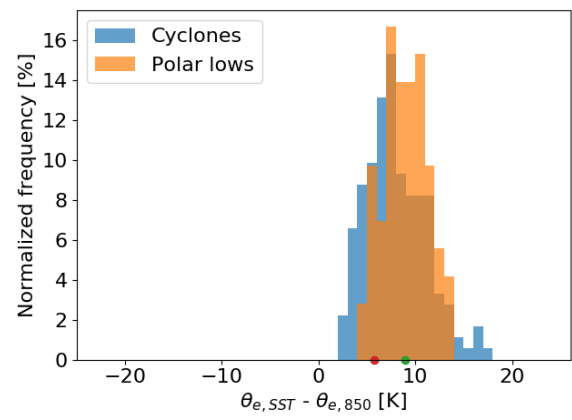

(f) $\theta_{e, S S T}-\theta_{e, 850}$ after PL-IC

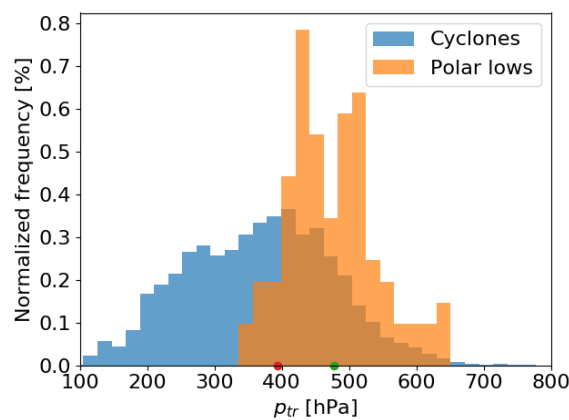

(i) $p_{t r}$

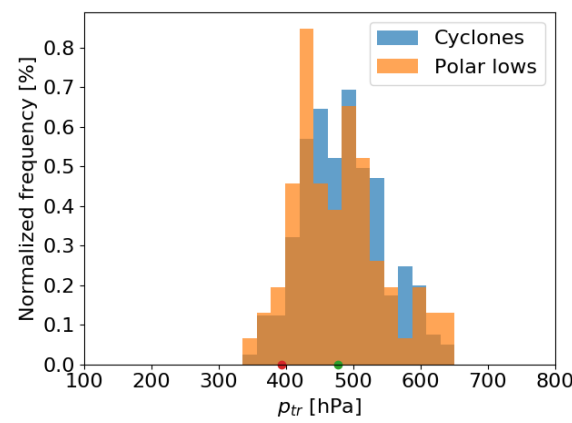

(l) $p_{t r}$ after PL-IC

Figure 3. Normalized distribution of the a) maximum $10 \mathrm{~m}$ wind speed in a radius of $220 \mathrm{~km}$, b) mean atmospheric column water in a radius of $110 \mathrm{~km}$, c) the maximum equivalent potential temperature difference between the sea surface and $700 \mathrm{hPa}$ within a radius of $110 \mathrm{~km}$, g) filtered vorticity at $850 \mathrm{hPa}$, h) maximum gradient of the equivalent potential temperature within a radius of $550 \mathrm{~km}$, and i) maximum tropopause pressure in a radius of $330 \mathrm{~km}$ around the system for all types of cyclones and PLs of ERA-I. The green and red dot mark the mean and the 10th percentile for a),c), g) and i) and the 90th percentile for b) and h) of the PLs. d) - f) and j) - l) same as a) - c) and $\mathrm{g}$ ) - i) but only for PLs and cyclones that satisfy the three PL-IC.

Kolstad (2011) suggested the use of the maximum value of the tropopause pressure $\left(p_{t r}\right)$ within a radius of $400 \mathrm{~km}$ to identify areas of upper-level forcing, a mechanism that Kolstad (2011) argued to be necessary for PL development. By taking the 5th percentile of a 
subjective PL dataset, Kolstad (2011) suggests a threshold of $p_{t r}>470 \mathrm{hPa}$ for the detection of PL favourable regions. In our study the threshold defined by the 10th percentile of the STARS-matched PLs is $p_{t r}>382 \mathrm{hPa}$, which is considerably weaker than the threshold from Kolstad (2011). In our study $p_{t r}$ is found to be less effective than other parameters for PL identification (see also Fig. 3i).

Terpstra et al. (2016) use the potential temperature at the tropopause $\left(\theta_{t r}\right)$ to indicate upper-level potential vorticity anomalies. This parameter appears effective to distinguish between PLs and other cyclones, however, slightly weaker than $\theta_{\mathrm{SST}}-\theta_{500}$ and redundant after application of the three PL-IC (see Table 2). The difference in the potential temperature of the sea surface and the tropopause $\left(\theta_{\mathrm{SST}}-\theta_{t r}\right)$ has the same score for cyclone exclusion as $\theta_{\mathrm{SST}}-\theta_{500}$, and the only reason for choosing the latter is that it excludes more cyclones after the other two PL-IC have been applied (column 6 in Fig. 2).

Also tested was whether the PBH could be an effective discriminator, as PLs are often found to be connected to a higher PBH than ether cyclones (Column 5 in Table 2). The high PBH is believed to be induced by the convection associated with the PLs. Another arameter, the total column water, shows in general lower values for PLs than for cyclones (see Fig. 3b), which can be explained by the occurrence of PLs in cold environments. However, both parameters appear to be less effective than most of the other stability measures. Most of the static-stability parameter perform best for PL detection, when the maximum value within a rather small radius (here $110 \mathrm{~km}$ ) is utilized. However, the difference to calculating the mean and choosing a larger radius is small (not shown).

\section{Polar-front criteria}

ree parameters are compared as polar-front criteria. The first parameter is the maximum gradient in the equivalent potential temperature at $850 \mathrm{hPa}$ poleward of the system $\left(\nabla \theta_{e, 850, p}\right)$. Since the main baroclinic zone is in general in the vicinity of the jet ream, by the thermal wind relation, the second and third parameters are based on the maximum wind speed poleward of the cyclone the tropopause $\left(U_{t r, p}\right)$ and at the $500 \mathrm{hPa}$ level $\left(U_{500, p}\right)$. The comparison reveals that the inspection of the strength of the jet stream

is more effective than the temperature gradient in the lower troposphere. The tropopause wind speed is more effective as a single parameter, while the $500 \mathrm{hPa}$ wind speed performs slightly better after the other two PL-IC are applied.

1

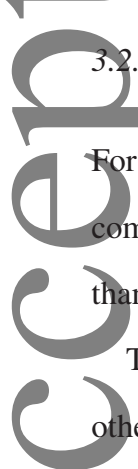

$A S R$

For ASR, 15018 cyclones for the months of Jan-Apr and Oct-Dec for the year 2003 in the ASR domain are considered for the omparison to the 123 identified STARS-matched PLs. As discussed above, fewer parameters are included in the comparison for ASR than for ERA-I.

The same procedure as for ERA-I is applied to the parameters in ASR, to investigate their efficacy in distinguishing between PLs and other cyclones. Results are summarized in Table 3. The 10th percentile boundary from PLs for the same parameters in ERA-I and in ASR (Column 4 in Table 2 and 3) are in general reasonably close to each other. This gives confidence that the same criteria can be used independently of the underlying dataset. Differences in thresholds can be due to a larger amount of the STARS PLs being recognized ASR than in ERA-I (123 vs. 94), and due to a difference in resolution of the two datasets. The precise comparison of the amount of the excluded cyclones in ERA-I and ASR by the 10th percentile threshold of different parameters (Column 5 in Table 2 and 3 ) has to be done with caution due to at least two reasons: Firstly, ASR includes cyclones of shorter minimum duration than does ERA-I ( 3 hourly vs. 6 hourly), and secondly, in ERA-I, all cyclones north of $30^{\circ} \mathrm{N}$ are included, while ASR includes cyclones in its whole domain, which is bounded by varying latitudes between $25-40^{\circ} \mathrm{N}$ (see Fig. 5c). Even though these limitations exist, the difference in the efficacy of the single parameters from ERA-I and ASR lies within 10 percent points.

This article is protected by copyright. All rights reserved. 
Table 3. As Table 2, but for ASR.

\begin{tabular}{|c|c|c|c|c|c|c|}
\hline Parameter & Type & $\begin{array}{c}\text { Radius } \\
{[\mathrm{km}]}\end{array}$ & $\begin{array}{l}\text { 10th percentile } \\
\text { of polar lows }\end{array}$ & $\begin{array}{c}\text { Excluded } \\
\text { cyclones [\%] }\end{array}$ & $\begin{array}{l}\text { Excluded cyclones } \\
\text { after } 2 \text { criteria [\%] }\end{array}$ & $\begin{array}{l}\text { Excluded cyclones } \\
\text { after } 3 \text { criteria [\%] }\end{array}$ \\
\hline$\xi_{f, 850}$ & point & 0 & $>4.27 \cdot 10^{-5} \mathrm{~s}^{-1}$ & 77.2 & 63.7 & 22.9 \\
\hline$U_{10 m}$ & $\max$ & 220 & $>17.4 \mathrm{~ms}^{-1}$ & 66.8 & 53.1 & 19.8 \\
\hline SLP - SLP & mean-point & 110 & $>0.44 \mathrm{hPa}$ & 73.7 & 60.9 & 10.7 \\
\hline$\overline{\text { SLP }}$ - SLP & mean-point & 330 & $>2.38 \mathrm{hPa}$ & 83.3 & 69.0 & 0 \\
\hline$T_{500}$ * & mean & 110 & $<240.4 \mathrm{~K}$ & 84.8 & 67.2 & 6.8 \\
\hline$T_{700}{ }^{\star}$ & mean & 110 & $<259.6 \mathrm{~K}$ & 75.1 & 59.4 & 7.6 \\
\hline $\mathrm{SST}^{\star}$ & mean & 110 & $<281.5 \mathrm{~K}$ & 54.9 & 24.5 & 15.6 \\
\hline $\mathrm{SST}-T_{500}$ & $\max$ & 110 & $>42.0 \mathrm{~K}$ & 85.3 & 77.4 & 4.5 \\
\hline $\mathrm{SST}-T_{700}$ & $\max$ & 110 & $>23.2 \mathrm{~K}$ & 74.1 & 73.4 & 10.7 \\
\hline$\theta_{\mathrm{SST}}-\theta_{500}$ & $\max$ & 110 & $>-8.5 \mathrm{~K}$ & 91.2 & 80.5 & 0 \\
\hline$\theta_{\mathrm{SST}}-\theta_{700}$ & $\max$ & 110 & $>-3.4 \mathrm{~K}$ & 80.9 & 75.7 & 6.8 \\
\hline$U_{500, p}{ }^{\star}$ & $\max$ & polew & $<29.6 \mathrm{~m} \mathrm{~s}^{-1}$ & 61.6 & 26.4 & 0 \\
\hline
\end{tabular}

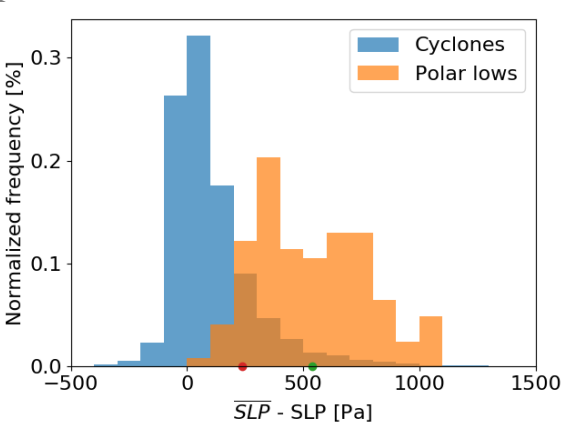

(a) $\overline{\text { SLP }}$ - SLP

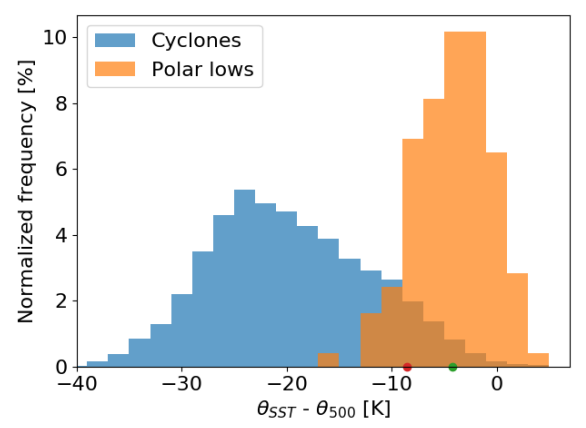

(b) $\theta_{\mathrm{SST}}-\theta_{500}$

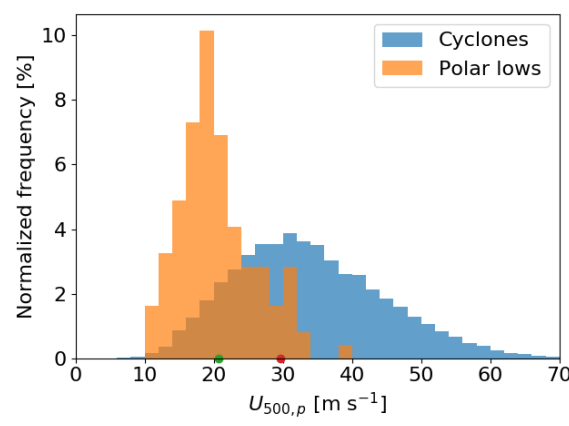

(c) $U_{500, p}$

Figure 4. Normalized distribution of the a) difference between the mean SLP in a radius of $330 \mathrm{~km}$ and the SLP of the cyclone centre, b) mean potential temperature difference between the sea surface and $500 \mathrm{hPa}$ within a radius of $110 \mathrm{~km}$, and c) the $500 \mathrm{hPa}$ wind speed poleward of the system for all types of cyclones and PLs of ASR. The green and red dot mark the mean and the 10th percentile for a) and b) and the 90th percentile for c) of the PLs. These criteria were found to be most effective for iscrimination between PLs and cyclones in ASR.

For ASR, the most effective of the investigated parameters for the exclusion of cyclones within each type of criteria are 1) the difference in the mean SLP within a radius of $330 \mathrm{~km}$ and the SLP of the cyclone centre, $\overline{\mathrm{SLP}}-\mathrm{SLP}>2.38 \mathrm{hPa}$, 2) the maximum difference of the potential temperature at the sea-surface and $500 \mathrm{hPa}$ within a radius of $110 \mathrm{~km}, \theta_{\mathrm{SST}}-\theta_{500}>-8.5 \mathrm{~K}$, and 3 ) the wind speed at $500 \mathrm{hPa}$ poleward of the system, $U_{500, p}<29.6 \mathrm{~m} \mathrm{~s}^{-1}$. The distributions of these three parameters for all types of cyclones and s are shown in Figure 4. They are the PL-IC for ASR and are only slightly different from those for ERA-I.

The SLP - SLP is more effective in ASR if the mean is calculated in a larger radius, compared to ERA-I. However, differences in the efficacy of different radii are relatively small. The threshold of SLP - SLP is dependent on the radius in which the mean is calculated, and the thresholds are in general close to each other for ASR and for ERA-I for the same radius.

The main difference within the compared parameters between ERA-I and ASR is observed for $U_{10 m}$, where the 10 th percentile threshold for PLs in ASR is much higher $\left(17.4 \mathrm{~m} \mathrm{~s}^{-1}\right)$ than in ERA-I (13.3 $\left.\mathrm{m} \mathrm{s}^{-1}\right)$. This can be explained by a better representation of the near-surface wind in ASR connected to PLs, as observed by Smirnova and Golubkin (2017). But even though the $U_{10 m}$ is more realistically represented in ASR than in ERA-I, both $\overline{\mathrm{SLP}}$ - SLP and $\xi_{f, 850}$ are found to be more skilful for PL identification.

The $\theta_{\mathrm{SST}}-\theta_{500}$ parameter is for both datasets more effective than the other MCAO criteria. The threshold of $\theta_{\mathrm{SST}}-\theta_{500}>-8.5 \mathrm{~K}$ is stricter than in ERA-I, where $-9.4 \mathrm{~K}$ is applied. This might be explained by the smoothening of local maxima due to the coarser 
resolution in ERA-I than in ASR. For other considered parameters within the MCAO criteria, the same findings as for ERA are obtained. The efficacy of these compared parameters for PL identification do not seem to depend much on the resolution of the dataset. This may be due to the large-scale character of MCAOs.

In ASR, $U_{500, p}$ is the only parameter included as a polar-front criterion. The fraction of excluded PLs by $U_{500, p}$ as an additional criterion suggests that this parameter improves the PL identification. Since in ERA-I the efficacy of $U_{t r, p}$ and $U_{500, p}$ are similar to each other, ASR is nudged by ERA-I at the upper boundary, and tropopause parameters for ASR are not directly accessible, it was considered sufficient to use $U_{500, p}$ for ASR.

As for ERA-I, the other parameters considered show distributions that are comparable for the STARS-matched PLs and the identified cyclones after the application of the three PL-IC (distributions not shown, but see last column of Table 3), giving confidence that the PL-IC for ASR are sufficient for PL identification, and that the identified cyclones can be considered PLs. Most of the STARS-matched s $(93$ out of $123=75.6 \%)$ include at least one time step where the three PL-IC are satisfied, called PL points, while only a small proportion of the cyclones include a PL point $(297$ out of $15018=2.0 \%)$. Thus, in ASR, a slightly smaller proportion of subjective PLs are excluded by the PL-IC, and a slightly lower proportion of the cyclones are classified as PLs as compared to ERA-I. This is an indication that the identified cyclones in ASR include less falsely excluded and falsely included PLs than ERA-I.

\section{Analysis of the climatologies}

order to detect PLs, the PL-IC derived in Section 3 are applied to all cyclones, which occur over open water poleward of $30^{\circ}$ for ERA-I and in the complete domain of ASR for the whole time span of the two reanalyses. To the knowledge of the authors, no PL has been reported between $30^{\circ} \mathrm{S}$ and $30^{\circ} \mathrm{N}$, and systems occurring within these latitudes would not be classified as being PLs, since the olar front is far poleward over open sea.

From the identified PLs, two climatologies are derived. One for the timespan 1979-2016 for ERA-I and one for 2000 - 2012 for ASR. In the following, these two climatologies are first briefly inspected and then analysed further in terms of their spatial and temporal distribution.

thas to be considered that the

\section{Inspection of the climatologies}

One way to test the climatologies is to investigate for "false hits". Inspection of some randomly picked PL cases from the climatologies reveals that most of these can be classified as being PLs or of the weaker form of polar mesoscale cyclones. Since the transition between being a PL and a mesoscale cyclone is fluent, a decision for a system being a PL is subjective. The counting of "true hits" and "false hits" strongly depends on a subjective decision on whether a system is regarded as a PL or not, hence this type of analysis was not performed. However, only a small fraction of the cases of the climatologies are clear and "beautiful" PLs. The climatology includes also solme cases of occluded synoptic-scale systems with convective signatures. These could possibly be excluded by applying a constraint on the size of the system. This is challenging for PLs, since automatic size-calculation of cyclones is often based on closed isobars (e.g. Rudeva and Gulev 2007). PLs, occurring in a pressure gradient that causes the MCAO, are not always local SLP minima, especially not in low-resolution reanalysis datasets, such as ERA-I (Laffineur et al. 2014).

The number of PLs in the derived climatologies can be compared to the STARS and Smirnova datasets. The STARS dataset includes 185 PLs in the Nordic Seas for the years 2000 - 2011. The climatologies include 911 PLs for ERA-I and 1321 PLs for ASR for the 


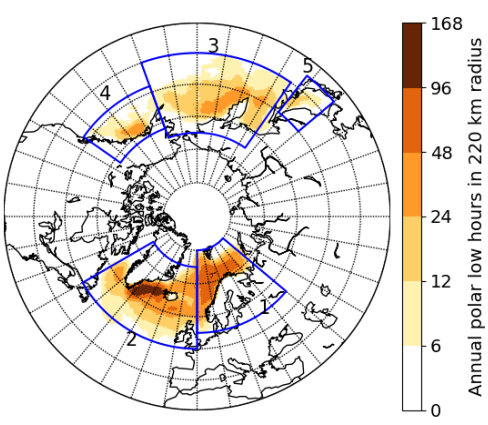

(a) ERA-I NH

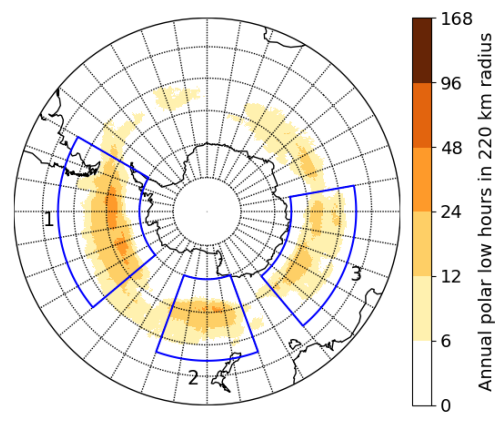

(b) ERA-I SH

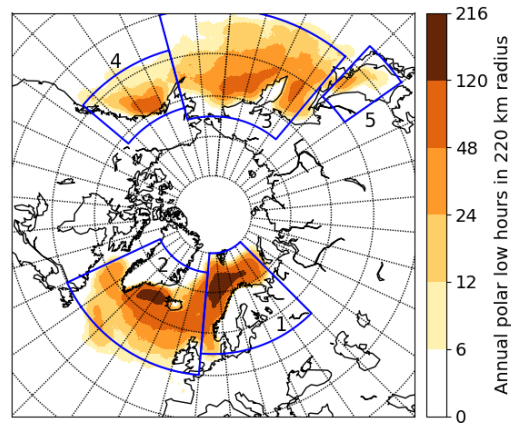

(c) ASR

Figure 5. Spatial distribution of the average annual polar-low duration within a radius of $220 \mathrm{~km}$ for a) the Northern and b) the Southern Hemisphere of ERA-I, and c) ASR.

C

me time period and approximately the same area as STARS. A possible explanation for this difference is that the STARS dataset

inçludes only clear PL cases, while the climatologies include a large amount of cases whose status as PL would be debated among

meteorologists. It is noted that other PL climatologies, such as the Smirnova database, find a considerably higher PL density. The Snhirnova dataset includes 637 PLs for the time period of 1995/96-2008/09 in the Nordic Seas. The derived climatology for ERA-I shows 709 cases for the same time period and approximately the same area as the Smirnova dataset. This reveals that other studies have found a similar PL density as those derived here.

An objective study of the "false misses" is impossible, since no accepted global PL dataset exists. However, a comparison with some existing PL climatologies is performed. Of the vaguely described 27 PLs in the period 1979-1982 from Wilhelmsen (1985), 22 PLs are identified in the climatology based on ERA-I. A one-to-one comparison cannot be performed due to the inaccurate description of PL tracks in Wilhelmsen (1985). Of the list presented in Yanase et al. (2016), 8 of the 19 PLs can be recognized in ERA-I and of 8 PLs in the years $2000-2012,4$ can be found in ASR and 2 in ERA-I. This reveals that the derived climatologies do not include all cases of other subjective PL datasets, but recognize a relevant proportion of them. It also should be noted that observational studies are subjective in nature.

are Spatial distribution of PLs

nother factor giving confidence in the climatologies is that the spatial and the temporal distribution is comparable to existing climatologies, as will be discussed in the following. The spatial annual-averaged distribution of PL duration is presented in Figure 5 for a) the Northern and b) Southern Hemisphere from ERA-I, and c) from ASR. The PL duration is calculated by multiplication of the number of detected PL points from the PL-IC of Section 3 with the time resolution of the dataset, which is 6 hours for ERA-I and 3 hours for ASR. This presentation of the average annual PL duration per area was chosen rather than the number of PLs, since the PL duration is considered to be a better measure of the PL activity in a region. A long-lasting PL contributes more to the PL activity than a short-lasting one, which is taken into account in the PL duration.

The spatial distribution of the climatologies in the NH between the two reanalyses shows similar patterns. They are in good agreement with that presented for the North Atlantic by Zahn and von Storch (2008), and of the North Pacific by Chen and von Storch (2013), even though different methodologies are used.

High PL density is often found in areas where Kolstad (2011) and Fletcher et al. (2016) detected a high frequency of MCAOs, e.g. in the Barents Seas and the Sea of Okhotsk, although this is not always the case. For example, the two studies found a relatively low 
frequency of MCAOs in the Denmark strait, which is here found as one of the major PL regions. Kolstad (2011) identified the Labrador Sea as the region with the most favourable PL conditions in the North Atlantic (see Section 1), while the Norwegian Sea south of $70^{\circ} \mathrm{N}$ shows rather unfavourable PL conditions, both in disagreement with our results. As opposed to the Kolstad (2011) approach, Zahn and von Storch (2008), Zappa et al. (2014), Yanase et al. (2016) and this study identify individual cyclones and apply criteria to determine whether they can be regarded as PLs.

Some regions of intense PL activity can be recognized: In ERA-I, the Denmark Strait, between the Southern tip of Greenland and Iceland, is identified as the region with the highest, and the Nordic Seas as the region with the second highest PL density of both hemispheres. This finding agrees with Zahn and von Storch (2008), who found that the Denmark Strait had the highest activity within the North Atlantic. In ASR, the Nordic Seas are recognized as having slightly higher PL activity than the Denmark Strait. This indicates that these two areas have the highest PL activity compared to the entire globe. Within the Nordic Seas, the highest PL density identified in an area around $72^{\circ} \mathrm{N}$ and $15^{\circ} \mathrm{E}$, also known as "Troms $\varnothing$ flake", which is in agreement with Noer et al. (2011).

The results suggest that more PLs occur in the North Atlantic (64\%) than in the North Pacific (36\%). On the Pacific side, the Gulf Alaska, the Bering Sea, the Sea of Okhotsk and the Sea of Japan are found to be PL active regions. PLs in the North Pacific occur as far south as $40^{\circ} \mathrm{N}$, while in the North Atlantic PLs are rarely identified south of $50^{\circ} \mathrm{N}$. In general, increased PL density is observed close to land masses or sea-ice edges and the density decreases in the direction of open sea. Yarnal and Henderson (1989) presented comparable maps of observed comma-cloud and spiral-form systems for the North Pacific with comma-cloud systems being observed far south as $40^{\circ} \mathrm{N}$, and with the occurrence of spiral systems often present in the vicinity of land masses. The maps in generally show high agreement with the density maps of the derived climatologies. Yanase et al. (2016) objectively identified PLs in the Sea of Japan and presented a spatial distribution of the PLs at their maximum intensity, similar to the results derived here from ERA-I and SR. Kolstad (2011) identified the same area in the Sea of Japan and the Sea of Okhotsk as favourable for PL development in the North Pacific, but did not recognize the areas to the east of this as being PL active.

In the $\mathrm{SH}$, most PL activity is found between 50 and $65^{\circ} \mathrm{S}$, with three areas showing increased activity: 1) the Bellingshausen and Amundsen Sea, 2) the Southern Sea south of New Zealand and 3) the Mawson and Davis Sea south west of Australia. 1) and 2) are the regions, where Kolstad (2011) found PL favourable conditions in the SH, but the third region was not identified in that study. Carleton and Carpenter (1990) identified more PLs at lower latitudes up to $30^{\circ} \mathrm{S}$, although their identification of PLs is based on atellite imagery and does not include criteria on intensity or the occurrence in an MCAO. The density of PL occurrence is in general fower than in active regions in the Northern Hemisphere (NH). Nevertheless, due to a larger ocean area, the SH has only $17 \%$ less PL tivity than the NH in ERA-I.

0

\section{Temporal distribution of PLs}

The average seasonal distributions of PL duration in ERA-I for the Northern and Southern Hemisphere and ASR are presented in Filgure 6a-c. PLs occur in the extended winter seasons of both hemispheres. In the NH, this is five months from November to March, with the maximum activity in January, some cases in April and October, and a few cases in May and September.

The hemispheric seasonal PL distribution cannot be compared with literature, since to our knowledge, no global PL climatology has been developed yet. However, seasonal distributions for different regions can be compared. This comparison has to be considered with caution, since the domains are often chosen differently. Also, other studies often count the PLs, while here, the duration of PL activity is presented.

This article is protected by copyright. All rights reserved. 


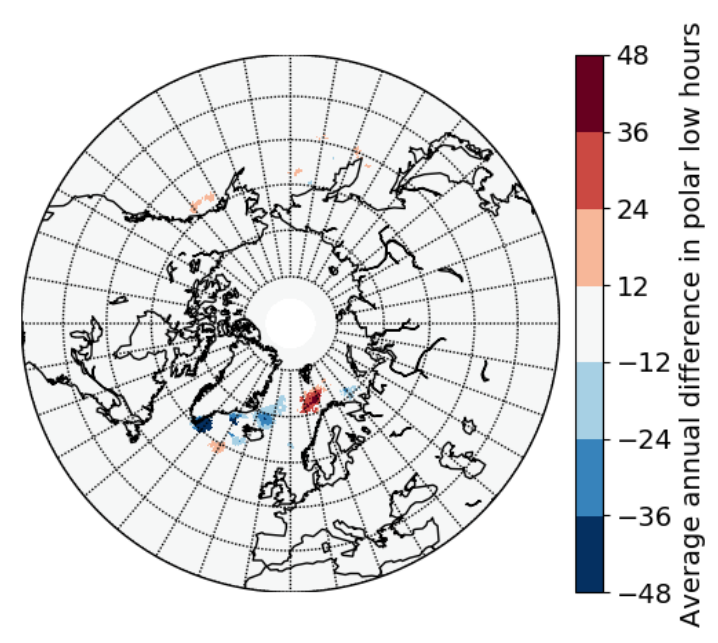

(a) $\mathrm{NH}$

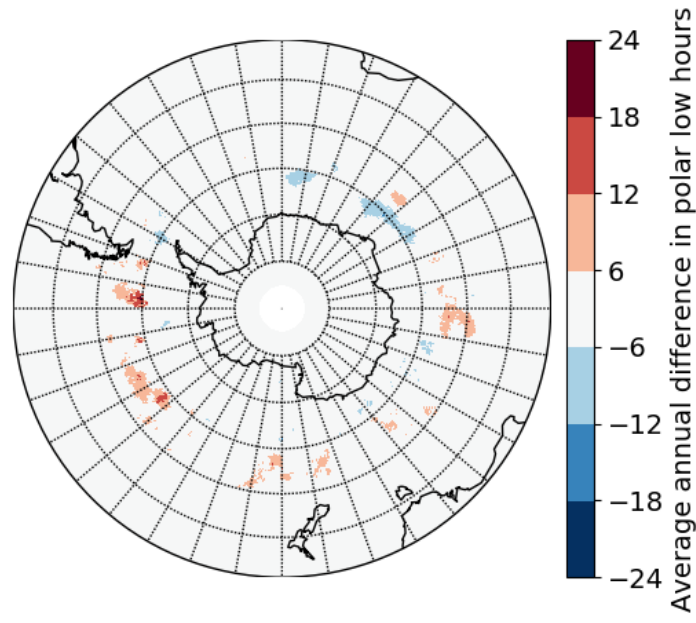

(b) $\mathrm{SH}$

\section{r}

Figure 7. Count density difference 2001 to 2016 minus 1979 to 1994 of average annual polar-low duration in ERA-I in a $220 \mathrm{~km}$ radius. Red colour shows areas with higher PL occurrence in the last 15 years. Only significant change with a p-value smaller than $5 \%$ by two-sided $t$-test is displayed.

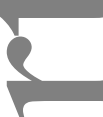

The trend in PL activity is negligible for the NH from ERA-I (0.07 PL points/year with p-value of 0.95 by a two sided $t$-test). ASR regarded as being too short for an investigation of a trend. For the SH, ERA-I shows an increasing trend of 1.3 PL points/year, which is not significant, with a p-value of 0.28. More interesting for the SH is the decade from 1992 to 2001 that shows strongly increased PL activity. The seven most PL active years during the period of ERA-I fall into this 10 year period.

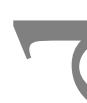

In Figure 7 the difference in PL occurrence in ERA-I in the last versus the first 15 years is compared, to identify regions of significant increasing and decreasing PL activity. The strongest decline in PL activity is observed east of Greenland's southern tip, and the highest (1)

increase on the Tromsø flake south of Svalbard, both with a change of up to 2 days of PL occurrence per year. In the Southern Ocean, increased PL activity is observed on the Northern side of PL active areas, while partly reduced activity is recognized closer to 1 Antarctica, leading to the suggestion that PL activity is propagating away from the continent. However, note that p-values smaller than by $t$-test can still be obtained by coincidence.

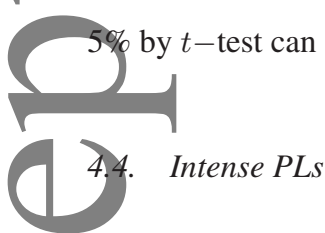

A climatology of the most intense PLs was also derived. In order to detect these systems, the 10th percentile threshold that is used in Section 3 is replaced by a threshold of the 50th percentile for both the intensity and the MCAO criteria, while the same polar-front criteria is used as before. Hereby the most intense PLs that develop in strong MCAOs are detected. For ERA-I (and ASR) this results in the detection criteria of $\overline{\mathrm{SLP}}-\mathrm{SLP}>0.71 \mathrm{hPa}(5.07 \mathrm{hPa})$ and $\theta_{\mathrm{SST}}-\theta_{500}>-4.4 \mathrm{~K}(-4.0 \mathrm{~K})$. The set of these thresholds excludes 73 of 94 ( 89 of 123) STARS PLs and retains only 21 of 8301 (21 of 15018) cyclones in the NH of the year 2003 for ERA-I (and ASR)

Hence only about $20 \%$ of the earlier identified PLs, now referred to as "all PLs", of the NH, are detected with these stricter thresholds.

The spatial distributions of intense PLs, presented in Figure 8a-c, resemble the distributions of all PLs depicted in Figure 5, with the difference that regions of high activity, being the Nordic Seas and the Denmark Strait, stand out more clearly. Most (about 75\%) of the intense PLs of the NH occur in the North Atlantic, and the SH shows only about 25\% intense PLs as compared to the NH.

The seasonal distributions of intense PLs, shown in Figure 8d-f, are in general more constrained to the winter months Dec - Mar in the NH and Jun -Aug in the SH. The time series of the annual duration of intense PLs in the NH, depicted in Figure 8g, has a significant 


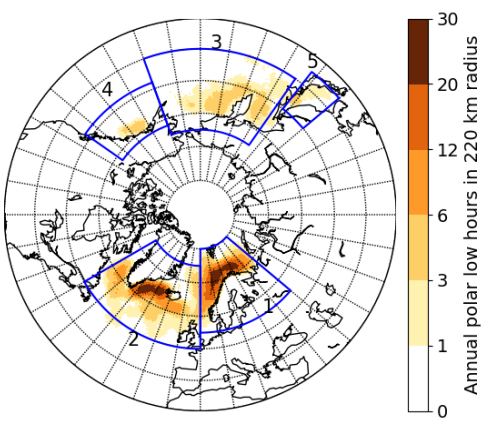

(a) ERA NH spatial distribution

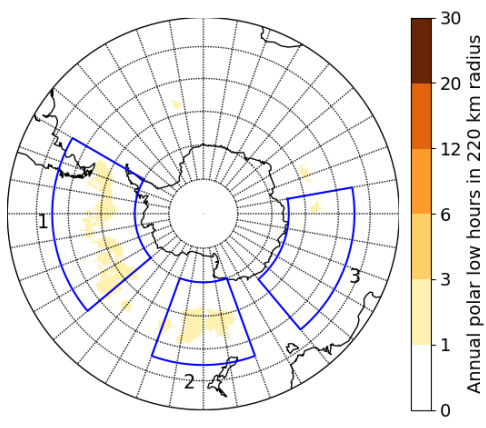

(b) ERA SH spatial distribution

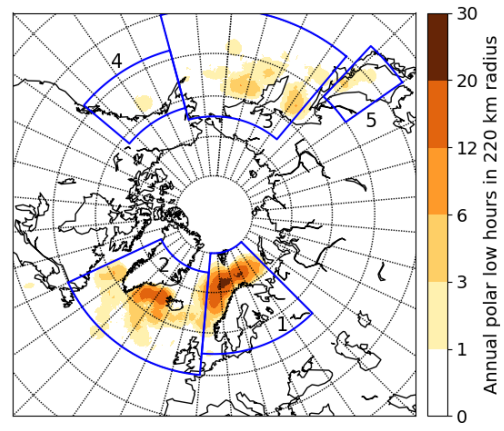

(c) ASR spatial distribution

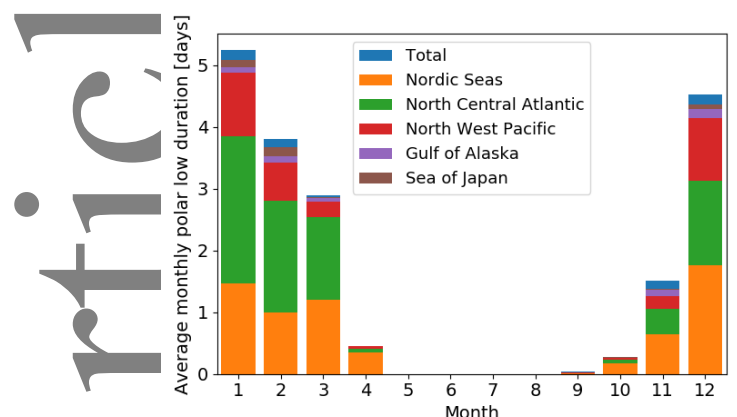

(d) ERA NH seasonal distribution

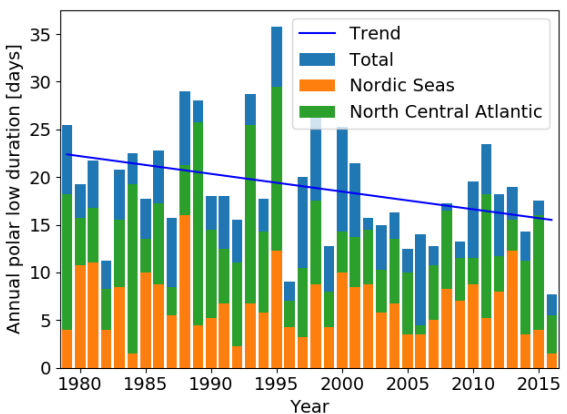

(g) ERA NH interannual distribution

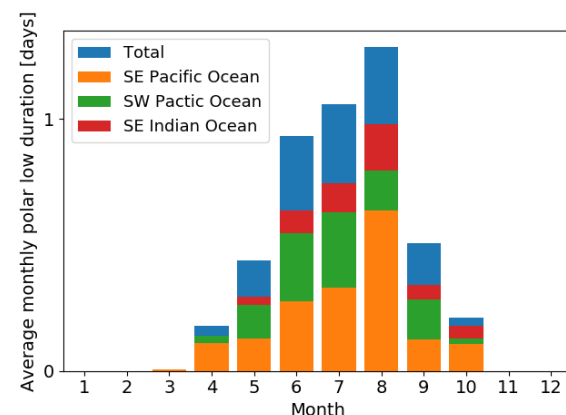

(e) ERA SH seasonal distribution

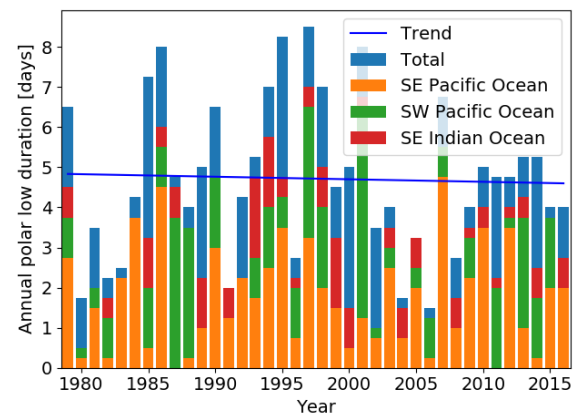

(h) ERA SH interannual distribution

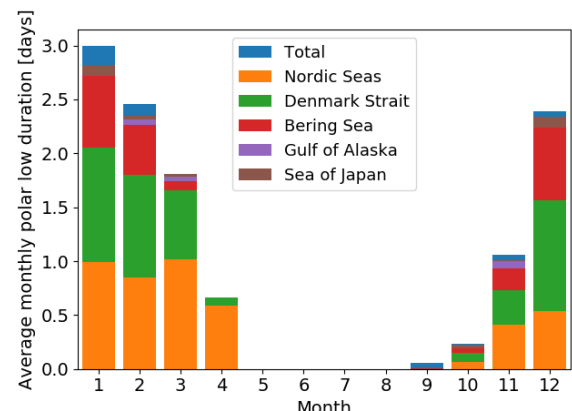

(f) ASR seasonal distribution

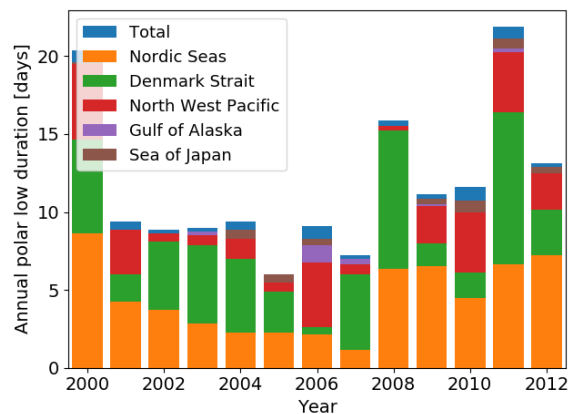

(i) ASR interannual distribution

Figure 8. Spatial and temporal distributions of the most intense PLs. a) - c) as Fig. 5, d) - i) as Fig. 6.

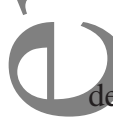

ecaying trend of -1.1 PL hour/year $(\mathrm{p}=0.034)$. This decaying trend is twice as strong in the Central North Atlantic as in the Nordic Seas.

A possible explanation for the decrease in intense PLs is a decline in the strength of MCAOs. Kolstad and Bracegirdle (2008) found a weakening of MCAOs from climate model projections for the end of the 21 st as compared to the end of the 20th century. However, to/the knowledge of the authors no study has observed a decay in the strength of MCAOs for the past decades.

\section{Discussion and Conclusion}

For the first time, an objective global PL climatology has been developed. The climatology is based on ERA-I and ranges from 1979 to 2016. A second climatology is derived from the higher resolution ASR reanalysis for the greater Arctic from 2000 to 2012 . Both climatologies are developed by applying constraints on cyclone tracks identified by a tracking algorithm based on spectrally filtered $850 \mathrm{hPa}$ vorticity data (Hodges 1995, 1999). The criteria were objectively developed by finding parameters that were most effective in separating between PLs from the subjective STARS database (Noer et al. 2011) and all kinds of mid- and high-latitude cyclones. 
For ERA-I (and ASR), the criteria were found to be 1) a difference of the mean SLP in a radius of $110 \mathrm{~km}(330 \mathrm{~km})$ and the SLP of the system larger than $0.4 \mathrm{hPa}(2.38 \mathrm{hPa}), 2)$ a maximum potential temperature difference in a radius of $110 \mathrm{~km}$ between the sea surface and $500 \mathrm{hPa}$ level above $-9.4 \mathrm{~K}(-8.5 \mathrm{~K})$, and 3$)$ the absence of tropopause $(500 \mathrm{hPa})$ wind of magnitude higher than $31.3 \mathrm{~m} \mathrm{~s}$ $\left(29.6 \mathrm{~m} \mathrm{~s}^{-1}\right)$ poleward of the system. Criteria 1 is applied to identify intense mesoscale systems, criteria 2 for the detection of MCAOs with connected deep convection, and criteria 3 to guarantee the occurrence of the systems poleward of the polar front. The result that the same parameters are found to be most effective for PL detection for both ERA-I and ASR, with thresholds only slightly stricter for ASR than for ERA-I, gives confidence that the criteria can be applied to other datasets as well.

Several other parameters (summarized in Table 1) were investigated for ERA-I and ASR, but none of them were found to improve detection of PLs as additional criteria. Importantly, a constraint on the near-surface wind speed, a commonly applied intensity criteria, is found to be much less effective for PL detection than criteria 1, a measure for the depth of the low. This applies for ERA-I, Where maximum winds connected to mesoscale systems are underrepresented, but also for ASR, even though it was found to better represent near-surface wind speeds (e.g. Smirnova and Golubkin 2017). It is therefore suggested not to use the $10 \mathrm{~m}$ wind speed for the detection of PLs from reanalyses.

The application of an MCAO criteria for PL detection is generally agreed upon, and it may be included to the PL definition by Rassmussen and Turner (2003), presented in the second paragraph of Section 1. Often, a temperature difference between the sea-surface and the $500 \mathrm{hPa}$ level of larger $43 \mathrm{~K}$, is utilized. Our analysis suggests that potential temperature performs better for PL detection than the actual temperature, and that the commonly used threshold of SST $-T_{500}>43 \mathrm{~K}$ is too strict, since it excludes a considerable proportion of PLs, which was also noted by Terpstra et al. (2016). A comparison of the temperature difference between the sea-surface and three atmospheric pressure levels reveals that the $500 \mathrm{hPa}$ is more useful for PL identification than the $700 \mathrm{hPa}$ and $850 \mathrm{hPa}$ level. This result is in disagreement with Bracegirdle and Gray (2008), although they used different temperature measures and a smaller set polar mesoscale cyclones, which includes systems that are too weak to be considered as PLs. Here, a new criteria is suggested, ensuring that only systems poleward of the polar front are detected. This criteria excludes about one third of the otherwise falselydetected cyclones and is therefore regarded as being important.

The investigation of our obtained climatologies reveals that they detect a significant fraction of the subjectively-identified PLs from STARS and other satellite-based PL dataset. Not all systems identified in our climatologies would be classified to be definite PLs, but only a few could be excluded by experts as clearly non PLs. This expresses the classical PL problem of not having an absolute objective efinition. In this study, as in other studies where PLs are identified objectively, all conditions for a PL have to be satisfied at the same time step, without considering the evolution of the cyclone. A more sophisticated approach would be to include all time steps of the system, when deciding, whether it should be classified as PL or not. The use of cyclone tracking algorithms, as done in this study, gives opportunity to apply this approach.

Due to the higher resolution of the ASR data as compared with ERA-I, the ASR climatology is regarded to be better than that based on ERA-I, although ASR has the disadvantage of having a shorter temporal coverage and a domain only for the NH. The two climatologies show similar spatial and temporal PL distributions. The Denmark Strait and the Nordic Seas are found to be the two most active PL regions. Also, other regions in the North Atlantic, the North Pacific and the Southern Seas between $65^{\circ}$ and $50^{\circ} \mathrm{S}$ were found to be PL active. It is observed that high PL activity occurs often in the vicinity of the sea-ice edge or the coast. The PL season ranges, generally, from November to March, with few cases in October and April for the NH. In the SH, the PL season is about two months 
longer, from April to October, with few cases in March and November, but less active. The annual PL activity is about $17 \%$ lower in the SH than in the NH. The most intense PLs are mainly constrained to the two most active PL regions and the core winter season.

The total annual PL occurrence for both hemispheres shows high interannual variability, but no significant trend during the period of ERA-I. However, in the SH a decade (1992 - 2001) of increased intensity was identified, and some regions in both hemispheres show changes in PL occurrence. The strongest decreasing trend is observed in the Denmark Strait and the highest increasing trend in the Nordic Seas to the south of Svalbard. Also, for the most intense PLs in the NH, a significant decaying trend was observed.

The derived PL climatologies can be used for further investigation of different PL types and of typical synoptic-scale patterns ssociated with PL development in different regions. It will be of interest to investigate the PL representation in the recently-derived, high-resolution global reanalysis ERA-5 and to derive a PL climatology based on this reanalysis once it is fully released. Also of relevance would be a comparison of, to which degree the derived criteria depend on the underlying subjective PL list, such as the TARS or Smirnova dataset.

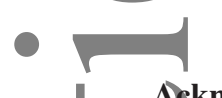

\section{Acknowledgements}

We thank the ERA-Interim development group at ECMWF and the ASR developers of the Polar Meteorology Group at Byrd Polar d Climate Research Center, The Ohio State University, for providing their reanalysis datasets. We also thank the employees at the Norwegian Meteorological Institute for listing PL tracks in the STARS database and making them public accessible. Data was processed in part by using the super computer Stallo at the University of Troms $\varnothing$ (UiT) provided by the Norwegian Metacenter for Computational Science (NOTUR) under the project NN9348K. The TRACK cyclone dataset is publicly available at the Norstore research data archive following the link https://archive.norstore.no/pages/public/datasetDetail.jsf?id=945E779C-54DE-4A9D-BCF6C767B15B8AE1. Finally, we thank two anonymous reviewers for their valuable comments.

$+$

\section{References}

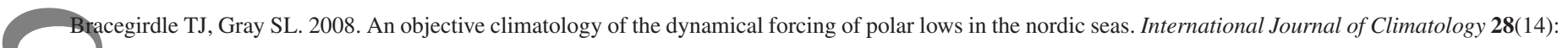
1903-1919.

Bracegirdle TJ, Kolstad EW. 2010. Climatology and variability of southern hemisphere marine cold-air outbreaks. Tellus A 62(2): 202-208.

romwich DH, Wilson AB, Bai L, Liu Z, Barlage M, Shih CF, Maldonado S, Hines KM, Wang SH, Woollen J, et al. 2017. The arctic system reanalysis version 2. Bulletin of the American Meteorological Society (2017).

romwich DH, Wilson AB, Bai LS, Moore GWK, Bauer P. 2016. A comparison of the regional arctic system reanalysis and the global era-interim reanalysis for the arctic. Quarterly Journal of the Royal Meteorological Society 142(695): 644-658.

usinger S. 1987. The synoptic climatology of polar-low outbreaks over the gulf of alaska and the bering sea. Tellus A: Dynamic Meteorology and Oceanography 39(4): 307-325.

Carleton AM, Carpenter DA. 1990. Satellite climatology of 'polar lows' and broadscale climatic associations for the southern hemisphere. International Journal of Climatology 10(3): 219-246.

Chen F, von Storch H. 2013. Trends and variability of north pacific polar lows. Advances in Meteorology 2013.

Dee DP, Uppala SM, Simmons AJ, Berrisford P, Poli P, Kobayashi S, Andrae U, Balmaseda MA, Balsamo G, Bauer P, et al. 2011. The era-interim reanalysis: Configuration and performance of the data assimilation system. Quarterly Journal of the Royal Meteorological Society 137(656): 553-597.

Emanuel KA, Rotunno R. 1989. Polar lows as arctic hurricanes. Tellus A 41(1): 1-17.

Fletcher J, Mason S, Jakob C. 2016. The climatology, meteorology, and boundary layer structure of marine cold air outbreaks in both hemispheres. Journal of Climate 29(6): 1999-2014. 
Fu G, Qin-Yu L, Zeng-Mao W. 1999. General features of polar lows over the japan sea and the northwestern pacific. Chinese Journal of Oceanology and Limnology 17(4): 300-307.

Hodges K. 1995. Feature tracking on the unit sphere. Monthly Weather Review 123(12): 3458-3465.

Hodges K. 1999. Adaptive constraints for feature tracking. Monthly Weather Review 127(6): 1362-1373.

Hoskins BJ, Sardeshmukh PD. 1984. Spectral smoothing on the sphere. Mon. Wea. Rev 112: 2524-2529.

Kolstad EW. 2011. A global climatology of favourable conditions for polar lows. Quarterly Journal of the Royal Meteorological Society 137(660): 1749-1761.

Kolstad EW, Bracegirdle TJ. 2008. Marine cold-air outbreaks in the future: an assessment of ipcc ar4 model results for the northern hemisphere. Climate Dynamics 30(7-8): 871-885.

Laffineur T, Claud C, Chaboureau JP, Noer G. 2014. Polar lows over the nordic seas: Improved representation in era-interim compared to era-40 and the impact on downscaled simulations. Monthly Weather Review 142(6): 2271-2289.

Michel C, Terpstra A, Spengler T. 2018. Polar mesoscale cyclone climatology for the nordic seas based on era-interim. Journal of Climate 31(6): 2511-2532.

U, Akperov MG, Bellenbaum N, Benestad R, Blender R, Caballero R, Cocozza A, Dacre HF, Feng Y, Fraedrich K, et al. 2013. Imilast: A community effort to intercompare extratropical cyclone detection and tracking algorithms. Bulletin of the American Meteorological Society 94(4): 529-547.

Noer G, Saetra Ø, Lien T, Gusdal Y. 2011. A climatological study of polar lows in the nordic seas. Quarterly Journal of the Royal Meteorological Society 137(660): 1762-1772.

Papritz L, Pfahl S, Sodemann H, Wernli H. 2015. A climatology of cold air outbreaks and their impact on air-sea heat fluxes in the high-latitude south pacific. Journal of Climate 28(1): 342-364.

Rasmussen EA, Turner J. 2003. Polar lows. Springer.

Rojo M, Claud C, Mallet PE, Noer G, Carleton AM, Vicomte M. 2015. Polar low tracks over the nordic seas: a 14-winter climatic analysis. Tellus A 67.

Rudeva I, Gulev SK. 2007. Climatology of cyclone size characteristics and their changes during the cyclone life cycle. Monthly weather review 135(7): 25682587.

$\int_{\operatorname{Prc}}^{\mathrm{Samu}}$

muelsen EM, Løset S, Edvardsen K. 2015. Marine icing observed on kv nordkapp during a cold air outbreak with a developing polar low in the barents sea. Proceedings of the 23rd International Conference on Port and Ocean Engineering under Arctic Conditions; 2015 Jun 14-18; Trondheim, Norway .

Smirnova JE, Golubkin PA. 2017. Comparing polar lows in atmospheric reanalyses: Arctic system reanalysis versus era-interim. Monthly Weather Review (2017).

Smirnova JE, Golubkin PA, Bobylev LP, Zabolotskikh EV, Chapron B. 2015. Polar low climatology over the nordic and barents seas based on satellite passive microwave data. Geophysical Research Letters 42(13): 5603-5609.

Smirnoya JE, Zabolotskikh EV, Bobylev LP, Chapron B. 2016. Statistical characteristics of polar lows over the nordic seas based on satellite passive microwave data. Izvestiya, Atmospheric and Oceanic Physics 52(9): 1128-1136.

Terpstra A, Michel C, Spengler T. 2016. Forward and reverse shear environments during polar low genesis over the north east atlantic. Monthly Weather Review (2016).

Wilhelmsen K. 1985. Climatological study of gale-producing polar lows near norway. Tellus A 37(5): 451-459.

Yanase W, Niino H, Watanabe SiI, Hodges K, Zahn M, Spengler T, Gurvich IA. 2016. Climatology of polar lows over the sea of japan using the jra-55 reanalysis. Journal of Climate 29(2): 419-437.

Yarnal B, Henderson KG. 1989. A climatology of polar low cyclogenetic regions over the north pacific ocean. Journal of Climate 2(12): 1476-1491.

Zahn M, von Storch H. 2008. A long-term climatology of north atlantic polar lows. Geophysical Research Letters 35(22).

Zappa G, Shaffrey L, Hodges K. 2014. Can polar lows be objectively identified and tracked in the ecmwf operational analysis and the era-interim reanalysis?

Monthly Weather Review 142(8): 2596-2608.

This article is protected by copyright. All rights reserved. 